\title{
A Simulation of the Separate Climate Effects of Middle-Atmospheric and Tropospheric $\mathrm{CO}_{2}$ Doubling
}

\author{
M. SIGMOND \\ Department of Applied Physics, Eindhoven University of Technology (TUE), Eindhoven, and Royal Netherlands Meteorological Institute \\ (KNMI), De Bilt, Netherlands \\ P. C. Siegmund \\ Royal Netherlands Meteorological Institute (KNMI), De Bilt, Netherlands \\ E. MANZINI \\ Istituto Nazionale di Geofisica e Vulcanologia, Bologna, Italy \\ H. KELDER \\ Department of Applied Physics, Eindhoven University of Technology (TUE), Eindhoven, and Royal Netherlands Meteorological Institute
} (KNMI), De Bilt, Netherlands

(Manuscript received 14 July 2003, in final form 27 November 2003)

\begin{abstract}
The separate climate effects of middle-atmospheric and tropospheric $\mathrm{CO}_{2}$ doubling have been simulated and analyzed with the ECHAM middle-atmosphere climate model. To this end, the $\mathrm{CO}_{2}$ concentration has been separately doubled in the middle-atmosphere, the troposphere, and the entire atmosphere, and the results have been compared to a control run. During $\mathrm{NH}$ winter, the simulated uniformly doubled $\mathrm{CO}_{2}$ climate shows an increase of the stratospheric residual circulation, a small warming in the Arctic lower stratosphere, a weakening of the zonal winds in the Arctic middle-atmosphere, an increase of the $\mathrm{NH}$ midlatitude tropospheric westerlies, and a poleward shift of the $\mathrm{SH}$ tropospheric westerlies. The uniformly doubled $\mathrm{CO}_{2}$ response in most regions is approximately equal to the sum of the separate responses to tropospheric and middle-atmospheric $\mathrm{CO}_{2}$ doubling. The increase of the stratospheric residual circulation can be attributed for about two-thirds to the tropospheric $\mathrm{CO}_{2}$ doubling and one-third to the middle-atmospheric $\mathrm{CO}_{2}$ doubling. This increase contributes to the Arctic lower-stratospheric warming and, through the thermal wind relationship, to the weakening of the Arctic middleatmospheric zonal wind. The increase of the tropospheric $\mathrm{NH}$ midlatitude westerlies can be attributed mainly to the middle-atmospheric $\mathrm{CO}_{2}$ doubling, indicating the crucial importance of the middle-atmospheric $\mathrm{CO}_{2}$ doubling for the tropospheric climate change. Results from an additional experiment show that the $\mathrm{CO}_{2}$ doubling above $10 \mathrm{hPa}$, which is above the top of many current GCMs, also causes significant changes in the tropospheric climate.
\end{abstract}

\section{Introduction}

The notion that the stratosphere influences the troposphere has been supported by many recent studies. Low-frequency zonal wind variations propagate downward from the upper stratosphere to the lower troposphere (e.g., Kodera et al. 1990). Anomalies in the leading mode of variability of the Northern Hemispheric (NH) circulation [known as either the Arctic Oscillation (AO) or the Northern Hemisphere annular mode (NAM): Thompson and Wallace 1998] generally first appear in

Corresponding author address: Dr. M. Sigmond, KNMI, P.O. Box 201, 3730 AE, De Bilt, Netherlands.

E-mail: sigmond@knmi.nl the stratosphere and propagate to the surface within several weeks (Baldwin and Dunkerton 1999). Several dynamical mechanisms for this downward propagation have been proposed: potential vorticity induction (Hartley et al. 1998), wave-mean flow interactions (e.g., Shindell et al. 2001) and meridional mass redistribution (Sigmond et al. 2003). During the last 30 years, the index corresponding to this leading mode of variability (the AO index) has undergone a positive trend, which can explain about $50 \%$ of the observed surface temperature increase over the Eurasian continent (Thompson et al. 2000). Since the AO is related to the midlatitude stratospheric zonal wind (e.g., Thompson et al. 2000), the observed warming may be partially due to changes in the stratospheric circulation. Several GCM studies predict an in- 
creased westerly circulation in the (lower) tropospheric NH midlatitudes (associated with a further increase of the $\mathrm{AO}$ index) in response to increasing $\mathrm{CO}_{2}$ concentrations (Shindell et al. 1999; Fyfe et al. 1999; Paeth et al. 1999; Gillett et al. 2002). The increase of greenhouse gases is believed to cool the polar stratosphere, to warm the tropical upper troposphere and, consequently, to increase the meridional temperature gradient in the tropopause region. Shindell et al. (2001) argue that this causes stratospheric zonal wind changes that in turn cause the increased westerly circulation in the tropospheric $\mathrm{NH}$ midlatitudes through wave-mean flow interactions. Several other GCM studies also indicate this downward influence (Boville 1984; Rind et al. 2002).

Other recent studies have addressed the question of how well the stratosphere has to be represented in GCMs to capture this downward influence adequately. Shindell et al. (1999) show that their model only captures the observed AO index increase if it includes the region between 10 and $0.01 \mathrm{hPa}$. However, Fyfe et al. (1999) and Gillett et al. (2002) found an AO index increase in response to increasing $\mathrm{CO}_{2}$ concentrations in models with an upper boundary at, respectively, 12 and $5 \mathrm{hPa}$. The latter result did not notably change when the upper boundary was raised to $0.01 \mathrm{hPa}$.

Greenhouse-gas-induced changes in the troposphere are expected to change the stratospheric circulation. Tropospheric waves propagate upward into the stratosphere, where they are dissipated and drive a meridional overturning circulation, known as the residual or BrewerDobson circulation (e.g., Holton et al. 1995). Tropospheric greenhouse gas increases can alter the sources and propagation patterns of the atmospheric waves that drive the stratospheric residual circulation. In a GCM experiment with increasing $\mathrm{CO}_{2}$, Butchart and Scaife (2001) found an increase of the strength of this circulation. They argued that such an increase would accelerate the removal of chlorofluorocarbons (CFCs) from the stratosphere and, consequently, accelerate the recovery of the ozone layer.

Rind et al. (1990) investigated the causes of the middle-atmospheric response to a uniform doubling of $\mathrm{CO}_{2}$, by performing experiments of one to three years timescale in which the $\mathrm{CO}_{2}$ was doubled in either the middleatmosphere or the troposphere. They suggested that the residual stratospheric circulation increase is due to both the "in situ" (middle-atmospheric) and the "remote" (tropospheric) $\mathrm{CO}_{2}$ doubling. The tropospheric response to $\mathrm{CO}_{2}$ doubling in either the troposphere or middleatmosphere was not considered in this study.

In the present study, the separate climate effects of middle-atmospheric and tropospheric $\mathrm{CO}_{2}$ increase are investigated with the middle-atmosphere version of the ECHAM global climate model. The control and uniformly doubled $\mathrm{CO}_{2}$ climate have been simulated. In addition, experiments have been performed in which the $\mathrm{CO}_{2}$ has been doubled in either the troposphere or the middle-atmosphere. These idealized experiments have been performed to study the mechanisms leading to the changes in the simulated uniformly doubled $\mathrm{CO}_{2}$ climate. Changes found in the uniformly doubled $\mathrm{CO}_{2}$ climate will be attributed to either middle-atmospheric or tropospheric $\mathrm{CO}_{2}$ doubling. We will investigate whether this separation is allowed, which requires that the response to a uniform $\mathrm{CO}_{2}$ doubling is approximately equal to the sum of the separate responses to tropospheric and middle-atmospheric $\mathrm{CO}_{2}$ doubling. We have performed 30-yr equilibrium experiments to obtain statistically significant results. Since the stratosphere-troposphere coupling is strongest in $\mathrm{NH}$ winter, we will focus on this season.

This paper is organized as follows. In section 2 the model and the setup of the experiments are described. In section 3 the control climate and the response to a uniform $\mathrm{CO}_{2}$ doubling is described. The climate responses to nonuniform (i.e., only tropospheric or middle-atmospheric) $\mathrm{CO}_{2}$ doubling are described in section 4. It is investigated to what extent the response to a uniform $\mathrm{CO}_{2}$ doubling can indeed be regarded as the sum of the responses to tropospheric and middle-atmospheric $\mathrm{CO}_{2}$ doubling. The downward influence of middle-atmospheric $\mathrm{CO}_{2}$ doubling on the troposphere is investigated in more detail in section 5. Finally, the results are summarized and discussed in section 6 .

\section{Model and setup of the experiments}

\section{a. The general circulation model}

The GCM used in this study is MA-ECHAM4 (Manzini et al. 1997), which is the middle-atmosphere version of the ECHAM4 model (Roeckner et al. 1996). The MAECHAM4 model has 39 levels from the surface up to $0.01 \mathrm{hPa}$ (about $80 \mathrm{~km}$ ). Gravity wave drag is parameterized for both orographic gravity waves (McFarlane 1987) and a spectrum of nonstationary gravity waves (Hines 1997a,b). Sensitivities to the specification of the gravity wave parameterizations are discussed by Manzini and McFarlane (1998). The simulations in this study are performed at $\mathrm{T} 42$ horizontal resolution (about $2.8^{\circ}$ $\times 2.8^{\circ}$ ) and the integration time step is set to 10 minutes. The ozone distribution (Brühl 1993) and the sea surface temperatures (SSTs) are prescribed.

\section{b. Experiments}

Six 30-yr simulations have been performed, whose configurations are summarized in Table 1. The atmospheric $\mathrm{CO}_{2}$ content has been doubled in the entire atmosphere from $353 \mathrm{ppmv}$ in the control run ( $\mathrm{C}$ run) to 706 ppmv in the uniformly doubled $\mathrm{CO}_{2}$ run (A run). Two additional runs have been performed in which the $\mathrm{CO}_{2}$ is separately doubled in the middle-atmosphere (M run) and the troposphere (T run). A monthly mean, longitude- and latitude-dependent tropopause field was used to select the regions where $\mathrm{CO}_{2}$ should be doubled 
TABLE 1. Summary of the configurations of the experiments, see section $2 b$.

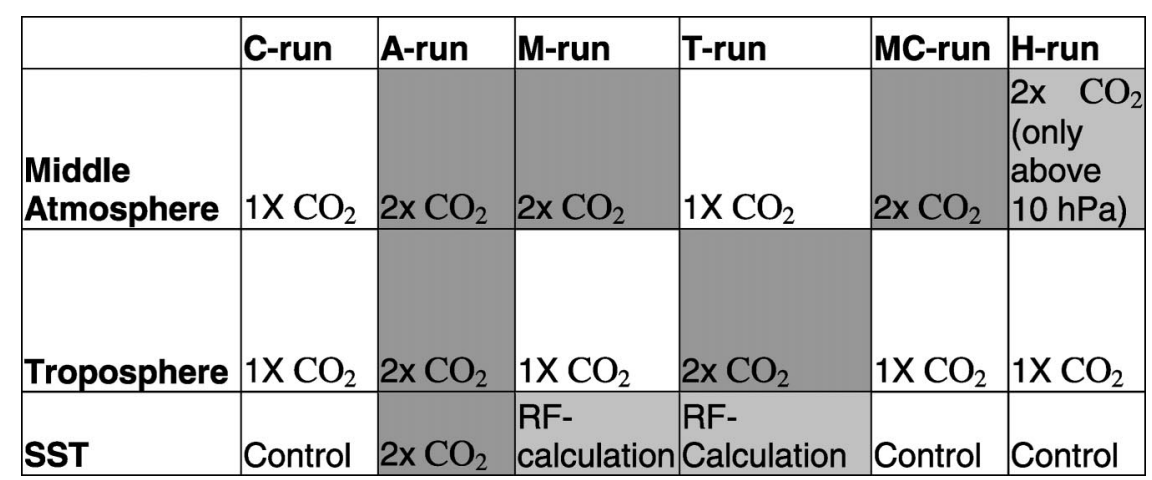

in the $\mathrm{M}$ and $\mathrm{T}$ runs. This climatology was calculated with the WMO tropopause definition and was taken from a control run of MA-ECHAM4.

The atmospheric GCM is not interactively coupled to an ocean model. Instead, monthly climatological SSTs are prescribed. In the $\mathrm{C}$ and $\mathrm{A}$ runs these SSTs are taken from a control and a doubled $\mathrm{CO}_{2}$ run of ECHAM4 coupled to a slab layer ocean. The appropriate SSTs in the $\mathrm{M}$ and $\mathrm{T}$ runs were calculated from these climatologies and calculated radiative forcings. The radiative forcing $(\mathrm{RF})$ is the net radiative flux change at the tropopause caused by a radiative perturbation (e.g., Houghton et al. 2001), and is generally considered as a useful measure for the surface temperature change. It is assumed that

$$
\mathrm{RF}_{\mathrm{A}}=\mathrm{RF}_{\mathrm{M}}+\mathrm{RF}_{\mathrm{T}},
$$

where $\mathrm{RF}_{\mathrm{X}}$ is the radiative forcing due to the $\mathrm{CO}_{2}$ doubling in region $\mathrm{X}$ ( $\mathrm{M}$ for middle-atmosphere, $\mathrm{T}$ for troposphere, and A for the entire atmosphere) and that the climate sensitivity parameter $\lambda\left(=\mathrm{RF} / \Delta T_{\text {surf }}\right)$ is the same for each $\mathrm{RF}_{\mathrm{X}}$. Under these conditions, it can be derived that

$$
\begin{aligned}
\Delta \mathrm{SST}_{\mathrm{T}} & =\Delta \mathrm{SST}_{\mathrm{A}} \times \text { frac }, \\
\Delta \mathrm{SST}_{\mathrm{M}} & =\Delta \mathrm{SST}_{\mathrm{A}} \times(1-\text { frac }),
\end{aligned}
$$

where

$$
\text { frac }=\frac{\mathrm{RF}_{\mathrm{T}}}{\mathrm{RF}_{\mathrm{T}}+\mathrm{RF}_{\mathrm{M}}} .
$$

The $\Delta \mathrm{SST}_{\mathrm{X}}$ is the change of SST compared to the control run due to the $\mathrm{CO}_{2}$ doubling in region $\mathrm{X}$. To compute $\mathrm{RF}_{\mathrm{X}}$, we have performed three additional integrations with the configurations of the $\mathrm{M}, \mathrm{T}$, and A runs, except that the control SSTs are prescribed. Here $\mathrm{RF}_{\mathrm{X}}$ is approximated by the global-mean net radiative flux change at the tropopause compared to the control run after one time step. From the results $\left(\mathrm{RF}_{\mathrm{M}}=0.64 \mathrm{~W} \mathrm{~m} \mathrm{~m}^{-2}, \mathrm{RF}_{\mathrm{T}}\right.$ $=3.26 \mathrm{~W} \mathrm{~m}^{-2}$ ) a value of 0.84 for frac is obtained. Since $\mathrm{RF}_{\mathrm{A}}=3.89 \mathrm{~W} \mathrm{~m}^{-2}$, Eq. (1a) appears to be valid almost exactly. Since frac is close to unity, the sea ice distribution in the $\mathrm{M}$ run is prescribed to be equal to that in the $\mathrm{C}$ run whereas the sea ice distribution in the $\mathrm{T}$ run is equal to that in the A run. The approach that we use is relatively simple because the possible dependency of $\lambda$ on the vertical location of the $\mathrm{CO}_{2}$ forcing is not considered and we calculated frac from instantaneous radiative forcings, whereas it would have been more appropriate to calculate it from the adjusted radiative forcings.

To investigate to what extent the imposed SST changes in the $M$ run influence the results, an additional run (denoted as the MC run) has been performed, which is similar to the $\mathrm{M}$ run except that the control SSTs are prescribed.

To investigate the influence of the $\mathrm{CO}_{2}$ doubling in the higher stratosphere and mesosphere on the tropospheric climate, a run has been performed in which the $\mathrm{CO}_{2}$ is doubled only above $10 \mathrm{hPa}(\mathrm{H}$ run). The radiative forcing due to the $\mathrm{CO}_{2}$ doubling above $10 \mathrm{hPa}$ is calculated in the same way as for the other runs and was found to be very small $\left(0.02 \mathrm{~W} \mathrm{~m}^{-2}\right)$. Therefore, control SSTs could be imposed in the $\mathrm{H}$ run.

\section{The climate response to a uniform $\mathrm{CO}_{2}$ doubling}

\section{a. The control climate}

Figures 1a and 1b show, respectively, the zonally averaged temperature and zonal wind in the control climate in NH winter. The temperature distribution, the strength of the NH stratospheric polar vortex, the subtropical jet streams, and the SH middle-atmospheric easterlies compare reasonably well with reference climatologies (Manzini and McFarlane 1998) except that the position of the polar vortex wind maximum $\left(60^{\circ} \mathrm{N}\right)$ is a bit too far poleward. The residual mean streamfunction [computed following the transformed Eulerian mean formulation (Andrews et al. 1987)] depicted in Fig. 1c shows the stratospheric residual circulation. This circulation is driven by the wave drag from planetary and gravity waves. The planetary waves are resolved by the model 
(a)

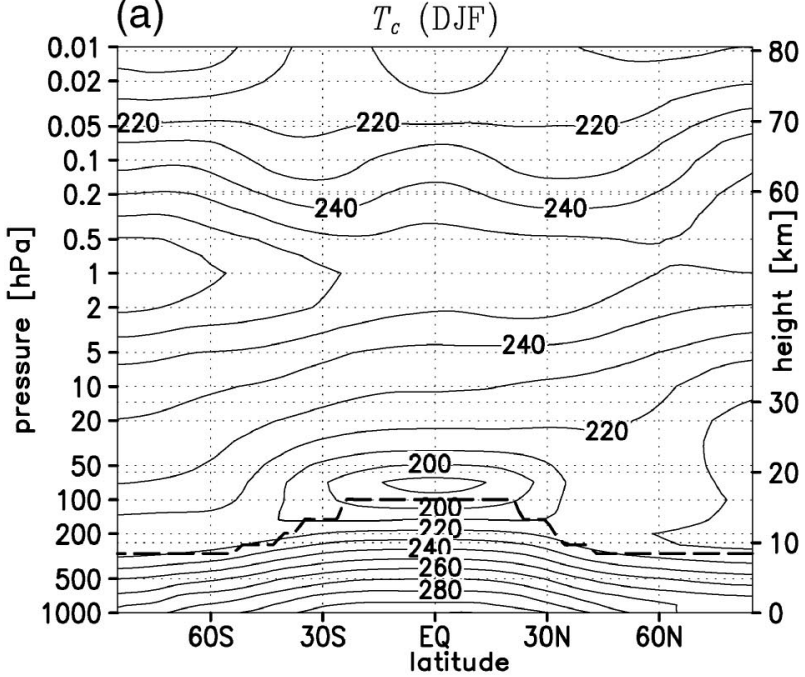

(c)

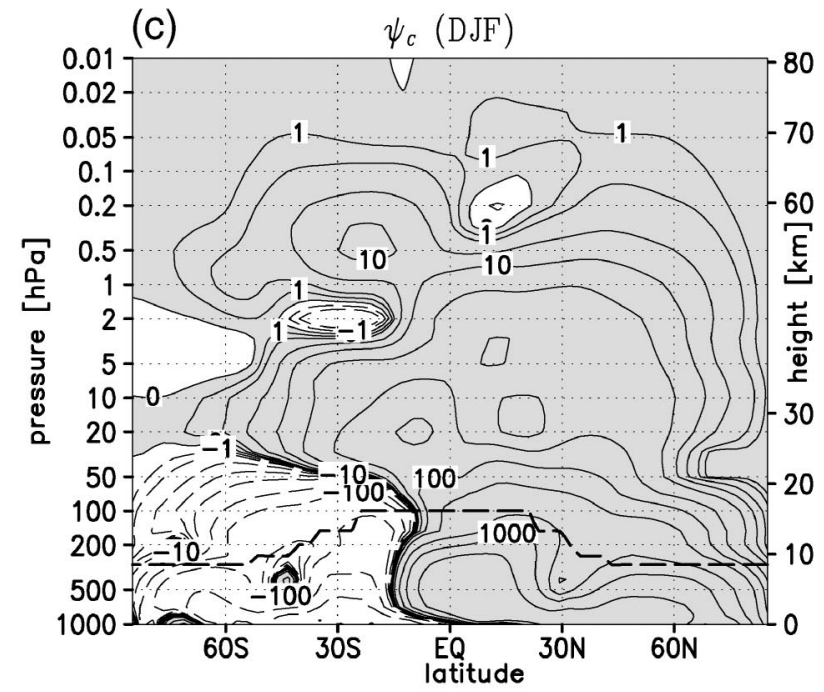

(e)

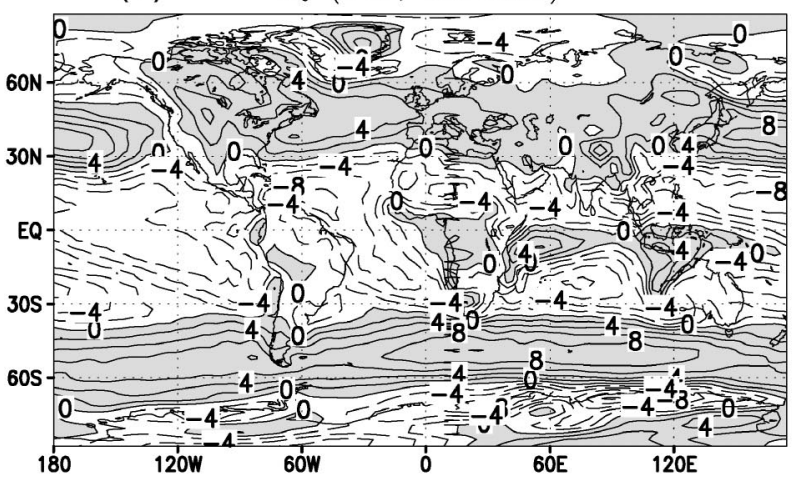

and their effect on the mean flow is quantified by $\operatorname{div} \mathbf{F} / \rho_{0}$ [where $\operatorname{div} \mathbf{F}$ is the divergence of the EliassenPalm (E-P) flux and $\rho_{0}$ is the density], which is shown in Fig. 1d. In regions where $\operatorname{div} \mathbf{F} / \rho_{0}$ is negative, the waves decelerate the zonal wind, thus causing an im-
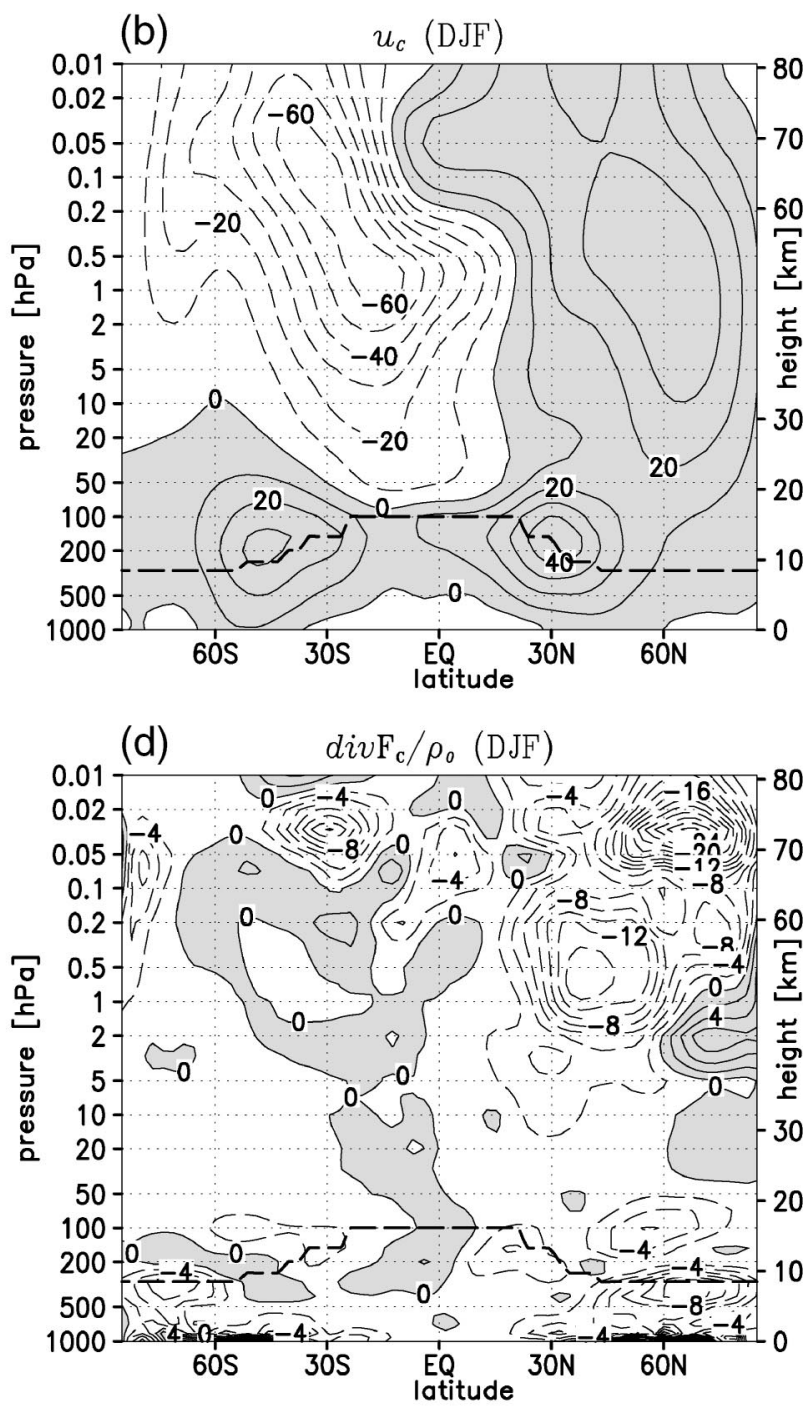

FIG. 1. The (a) zonally averaged temperature and (b) zonal wind, (c) the residual streamfunction, (d) the divergence of the E-P flux divided by density, and (e) the surface-level zonal wind in the $\mathrm{C}$ run. Results are averages over 30 years for the DJF season, and shading indicates positive values. The contour interval is, respectively, $10 \mathrm{~K}$ in (a), $10 \mathrm{~m} \mathrm{~s}^{-1}$ in (b), $2 \mathrm{~m} \mathrm{~s}^{-1}$ day $^{-1}$ in (d) and $2 \mathrm{~m} \mathrm{~s}^{-1}$ in (e). The contour lines in (c) are at $0, \pm 1, \pm 2, \pm 5, \pm 10, \pm 20, \pm 50$ $\mathrm{kg} \mathrm{m}^{-1} \mathrm{~s}^{-1}$, etc. The bold dashed line in (a)-(d) denotes the position of the zonally averaged tropopause.

balance between the Coriolis force on the zonal-mean zonal wind and the meridional pressure gradient force, driving a poleward flow. The surface zonal wind (Fig. 1e) is largest in the northern Atlantic and Pacific storm track regions and in the $\mathrm{SH}$ midlatitudes. 
In this paper, we will focus on the December-February (DJF) season, that is, $\mathrm{NH}$ winter and $\mathrm{SH}$ summer. In this season the zonal wind in the $\mathrm{SH}$ middle-atmosphere is easterly (Fig. 1a), constituting a barrier for the transport of tropospheric wave activity into the middleatmosphere (Charney and Drazin 1961). Consequently, in this season no strong stratosphere-troposphere interactions are expected in the Southern Hemisphere, in contrast to in the Northern Hemisphere. Therefore, the differences between the Northern and the Southern Hemisphere discussed in this paper are not caused by hemispheric differences, but by seasonal differences.

\section{b. The middle-atmospheric response to uniform $\mathrm{CO}_{2}$ doubling}

Figure $2 \mathrm{a}$ shows the zonally averaged temperature difference between the $\mathrm{A}$ run and the $\mathrm{C}$ run in $\mathrm{NH}$ winter (denoted as $\Delta T_{A}$ ). As expected, the middle-atmosphere generally cools in response to the uniform $\mathrm{CO}_{2}$ doubling, which can be explained by radiative arguments (e.g., Fels et al. 1980; Shindell et al. 2001). The changes are statistically significant, except in some regions where the changes are small. The main exception to the middle-atmospheric cooling is the Arctic lower stratosphere, which slightly warms. Figure $2 \mathrm{~b}$ shows the zonally averaged zonal wind difference between the $\mathrm{A}$ and the $\mathrm{C}$ run in $\mathrm{NH}$ winter $\left(\Delta u_{A}\right)$, which is physically consistent with Fig. 2a according to the thermal wind relationship. The warming of the Arctic lower stratosphere and the reduced cooling directly above this layer lead to a decrease of the meridional temperature gradient in the polar stratosphere, consistent with the weakening of the Arctic middle-atmospheric zonal winds. The zonal wind in the NH subtropical middle-atmosphere strengthens, with up to $9 \mathrm{~m} \mathrm{~s}^{-1}$ near the stratopause and just above the NH subtropical jet stream. The position of the maximum wind speed in the polar vortex has shifted equatorward from $60^{\circ} \mathrm{N}$ in the $\mathrm{C}$ run to $40^{\circ} \mathrm{N}$ in the $\mathrm{A}$ run, and its value has decreased from $38 \mathrm{~m} \mathrm{~s}^{-1}$ in the $\mathrm{C}$ run to $34 \mathrm{~m} \mathrm{~s}^{-1}$ in the A run (not shown). In the Southern Hemisphere, the middle-atmospheric extratropical easterlies significantly decrease in magnitude.

Figure $2 \mathrm{c}$ shows the change of the residual streamfunction in the A run compared to the $\mathrm{C}$ run $\left(\Delta \psi_{A}\right)$. The strength of the stratospheric residual circulation generally increases except in the tropical middle stratosphere. The maximum of the NH residual streamfunction, which is located between $15^{\circ}$ and $18^{\circ} \mathrm{N}$ and is a measure for the $\mathrm{NH}$ extratropical mass flux from the stratosphere to the troposphere (e.g., Rosenlof and Holton 1993), significantly increases $33 \%$ at $50 \mathrm{hPa}$ and $39 \%$ at $100 \mathrm{hPa}$. Associated with this increase, the descending motions near the North Pole increase. While adiabatically heating the air, they contribute to the temperature increase shown in Fig. 2 a.

To get an idea of the causes of the increased NH extratropical residual circulation, the change of the re- sidual meridional wind is investigated. Figure 3 a shows for the A run in the $\mathrm{NH}$ extratropics the change of the residual meridional wind, from which the streamfunction change depicted in Fig. $2 \mathrm{c}$ has been computed. This residual meridional wind is defined as [Andrews et al. 1987, Eq. (3.5.1a)]

$$
v^{*} \equiv \bar{v}-\rho_{0}^{-1} \frac{\partial\left[\rho_{0} \overline{v^{\prime} \theta^{\prime}}(\partial \bar{\theta} / \partial z)^{-1}\right]}{\partial z},
$$

where $\rho_{0}$ is the density, $v$ is meridional wind, and $\theta$ is the potential temperature. The overbar denotes the zonal-mean value; the prime denotes the deviation from that value. Figure 3a shows that in most of the NH extratropical stratosphere $v^{*}$ increases in the doubled $\mathrm{CO}_{2}$ climate, which corresponds to the increased residual circulation. Figure $3 \mathrm{~b}$ shows the part of $\Delta v_{A}^{*}$ that is due to resolved waves (denoted as $\Delta v_{A}^{*, \text {,resolved }}$ ). The $v^{* \text {,resolved }}$ has been computed by applying the continuity equation to the vertical velocity due to planetary wave driving, assuming "downward control" (Haynes et al. 1991). Since the analysis is focused on the extratropics, the quasigeostrophic approximation can be applied. Assuming quasigeostrophy and stationarity, this vertical velocity can be written as

$$
w^{* \text {,resolved }}=\frac{1}{a \rho_{0} \cos \phi} \frac{\partial}{\partial \phi}\left[\int_{z}^{\infty}\left(\frac{\cos \phi \operatorname{div} \mathbf{F}}{f}\right)_{\phi=\text { const. }} d z^{\prime}\right]
$$

where $a$ is the radius of the earth, $\phi$ is latitude, and $f$ is the Coriolis parameter. Comparison of Figs. $3 \mathrm{~b}$ and 4a for the resolved waves shows that the structure of

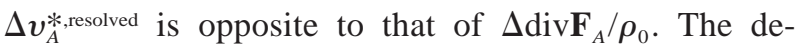
creased (i.e., more negative) $\operatorname{div} \mathbf{F}_{A} / \rho_{0}$ in the large part of the $\mathrm{NH}$ stratosphere implies that the wave drag due to the resolved waves on the zonally averaged zonal flow increases, and that the resolved waves strengthen

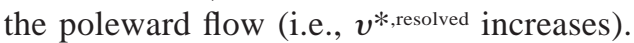

In the extratropical stratosphere and mesosphere, changes in the direct thermally forced component of $v^{*}$ are expected to be small. Therefore, the part of the change in $v^{*}$ that is not due to resolved waves (denoted as $\Delta v_{A}^{*}$,residual) in these regions is expected to be mainly due to unresolved gravity waves. In the NH midlatitude stratosphere $\Delta v_{A}^{*, \text { residual }}$ is comparable to $\Delta v_{A}^{\text {,resolved. In }}$ some stratospheric regions (e.g., region 1) $\Delta v_{A}^{*}$ is even mainly due to $\Delta v_{A}^{*}$,residual. Therefore, it is concluded that changes in both the resolved waves and other processes (of which gravity waves are expected to be the most important) drive the increased stratospheric $\mathrm{NH}$ extratropical residual circulation in the doubled $\mathrm{CO}_{2}$ climate. In the mesosphere, planetary wave activity is very small due to absorption of these waves at lower levels, which 

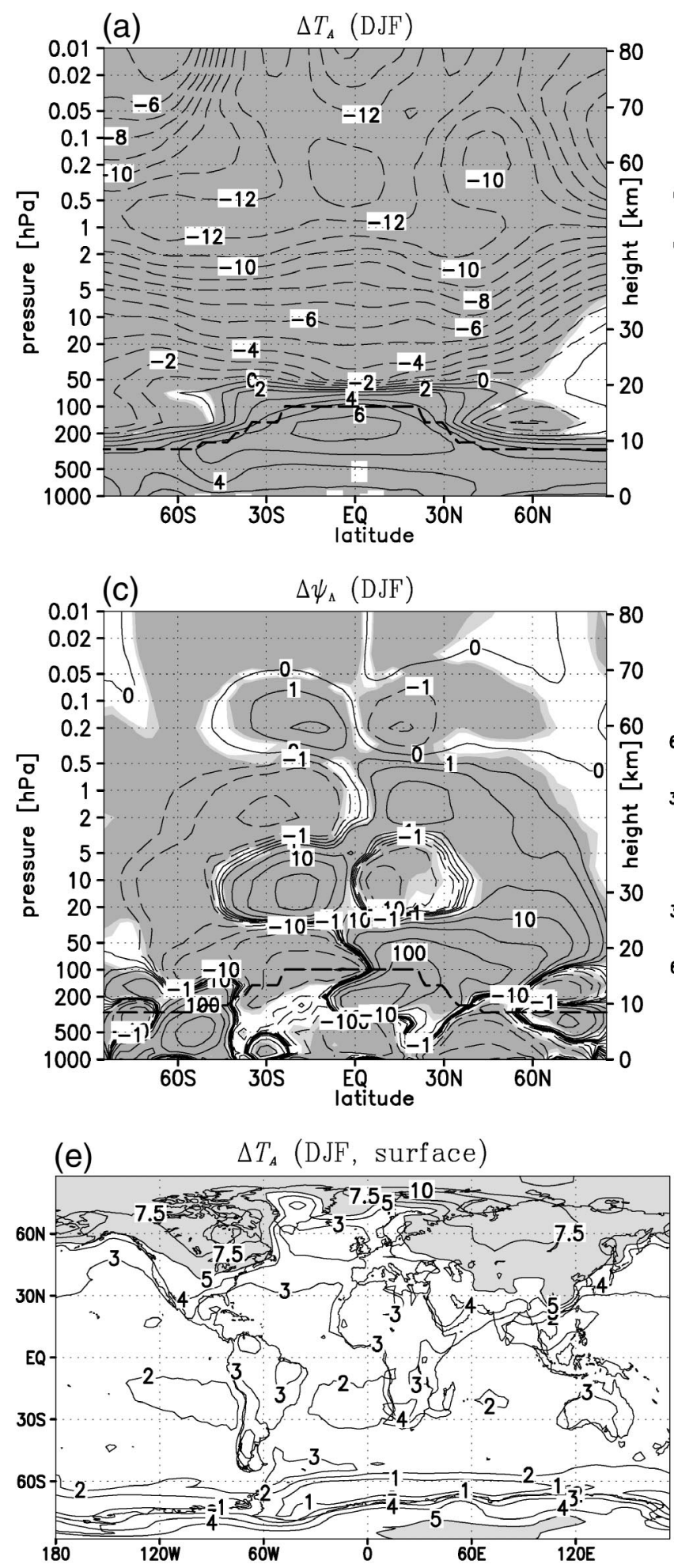

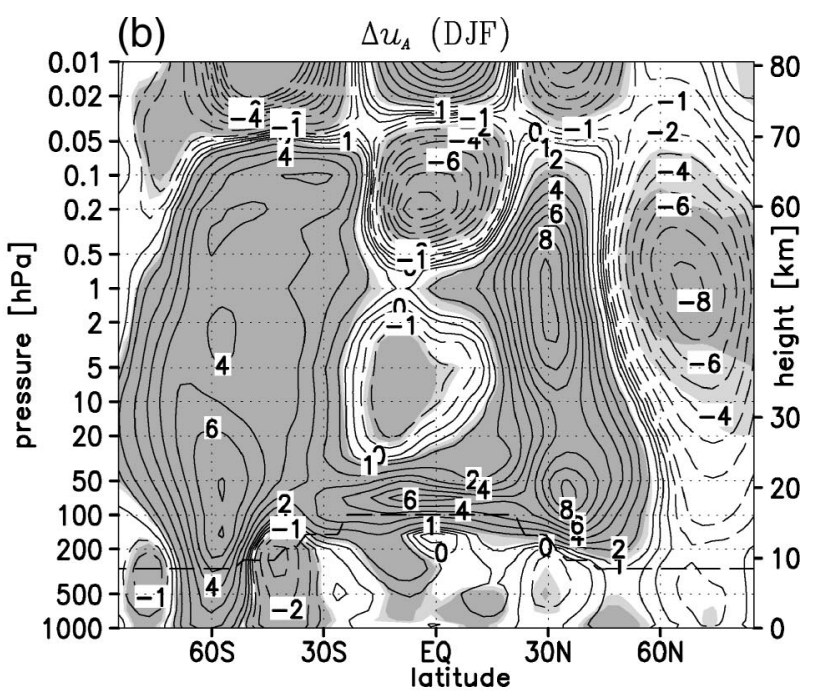

(d) $\quad \Delta u_{A}(\mathrm{DJF}$, surface)

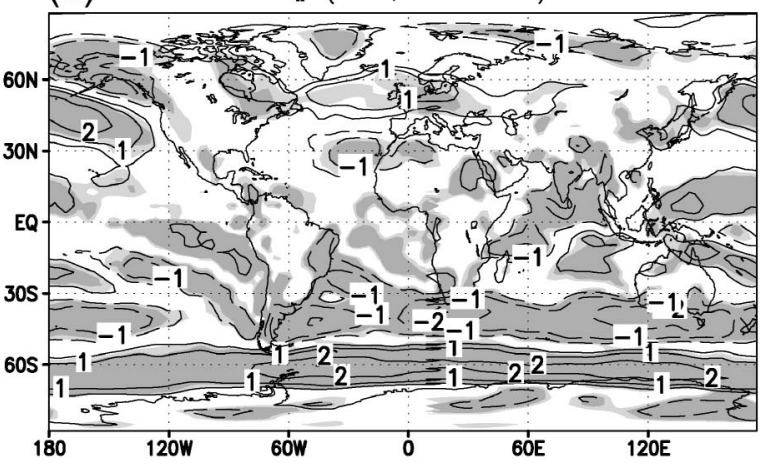

FIG. 2. (a)-(c), (d) As in Figs. 1a-c,e except for the difference between the $\mathrm{A}$ and $\mathrm{C}$ runs, and light (dark) shaded areas indicate regions where the difference is statistically significant at $95 \%(99 \%)$ level. The contour interval is $1 \mathrm{~K}$ in (a), the contour lines are at $0, \pm 0.5, \pm 1, \pm 2, \pm 3 \mathrm{~m} \mathrm{~s}^{-1}$, etc. in (b) and (d) and at $0, \pm 1, \pm 2, \pm 5, \pm 10, \pm 20, \pm 50 \mathrm{~kg} \mathrm{~m}^{-1} \mathrm{~s}^{-1}$, etc. in (c). The zero contour line in (d) has been omitted. (e) The surface air temperature difference between the A run and $\mathrm{C}$ run for the DJF season. Contours are at 1, 2, 3, 4, 5, 7.5, and $10 \mathrm{~K}$ and shading indicates values higher than $5 \mathrm{~K}$. can explain why in this region $\Delta v_{A}^{*}$,resolved is generally smaller than $\Delta v_{A}^{*}$,residual. Thus, the mesospheric $\Delta v_{A}^{*}$ is mainly determined by gravity waves drag changes.

Figure 4a shows that in the NH stratosphere the pat- tern of the $\Delta \operatorname{div} \mathbf{F}_{A} / \rho_{0}$ is similar to that of $\Delta u_{A}$ (Fig. 2b): they both decrease in the polar region and increase around $40^{\circ} \mathrm{N}$. This finding is consistent with the fact that $\operatorname{div} \mathbf{F} / \rho_{0}$ is a force on the zonal-mean zonal wind. 
(a)

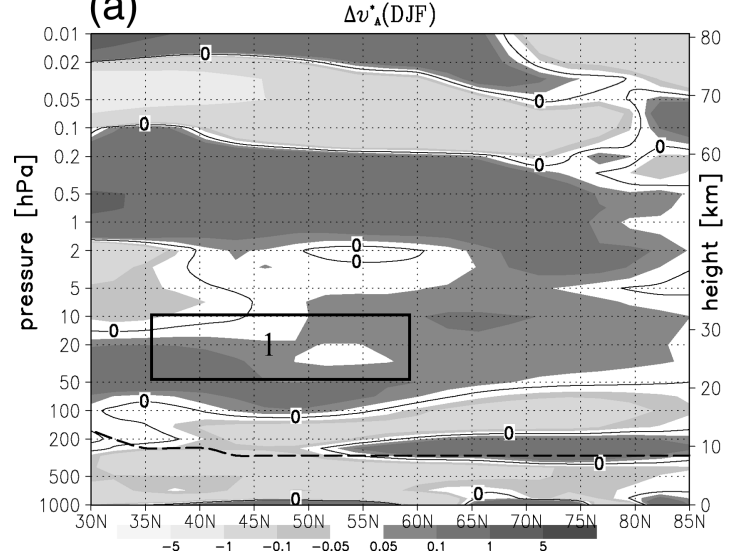

(b)

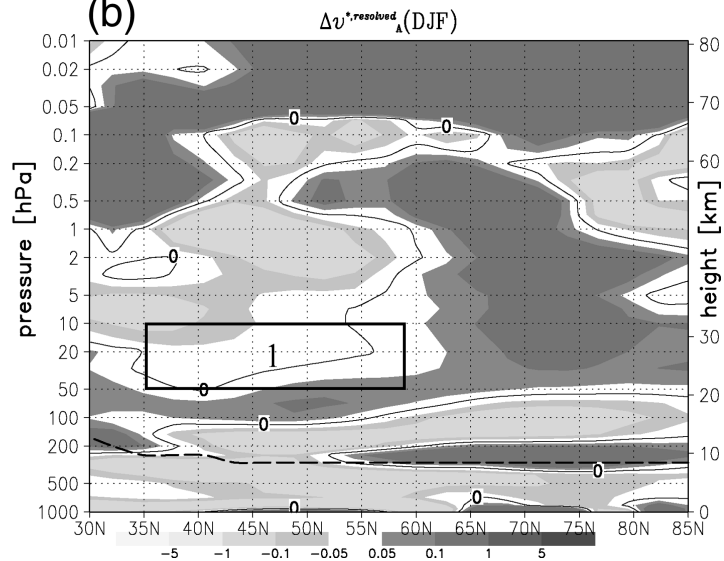

FIG. 3. The difference between the $\mathrm{A}$ and $\mathrm{C}$ runs of (a) $v^{*}$ and (b) $v^{* \text {,resolved }}$, for $\mathrm{NH}$ winter. The zero contour line is plotted. See section $3 \mathrm{~b}$ for the meaning of the symbols. Only the NH extratropics are plotted.

The changes in the resolved waves are investigated in more detail by decomposing $\operatorname{div} \mathbf{F} / \rho_{0}$ in its horizontal and vertical components $\operatorname{div} \mathbf{F}^{y} / \rho_{0}$ and $\operatorname{div} \mathbf{F}^{z} / \rho_{0}$, which in the quasigeostrophic approximation are given by

$$
\begin{aligned}
\operatorname{div} \mathbf{F}^{y} & =\frac{\partial}{\partial y} F^{y}, \\
\operatorname{div} \mathbf{F}^{z} & =\frac{\partial}{\partial z} F^{z}, \\
F^{y} & =-\rho_{0} \overline{u^{\prime} v^{\prime}}, \\
F^{z} & =\rho_{0} f a \cos \phi \overline{v^{\prime} \theta^{\prime}}(\partial \bar{\theta} / \partial z)^{-1} .
\end{aligned}
$$

Here $F^{y}$ and $F^{z}$ are, respectively, the horizontal and vertical component of the Eliassen-Palm flux vector, which is in the direction of the wave activity: $F^{z}$ is generally positive, corresponding to an upward propa- gation of the wave activity, and a positive $F^{y}$ corresponds to a poleward propagation of wave activity. Figure 4 shows that in the $\mathrm{NH}$ upper stratosphere (region I) and in the $\mathrm{NH}$ subtropical lower stratosphere (region II) the structure of $\Delta \operatorname{div} \mathbf{F}_{A} / \rho_{0}$ (Fig. 4a, shaded) is mainly determined by $\Delta \operatorname{div} \mathbf{F}_{A}^{y} / \rho_{0}$ (Fig. 4b, shaded), whereas in the $\mathrm{NH}$ midlatitude middle stratosphere (region III) it is mainly determined by $\operatorname{div} \mathbf{F}^{z} / \rho_{0}$ (Fig. $4 \mathrm{c}$, shaded). Changes in $\operatorname{div} \mathbf{F}^{y} / \rho_{0}$ are related to changes in $F^{y}$ and, consequently, to changes in the meridional refraction of wave activity. For example, in the middle of region II $F^{y}$ (Fig. 4b, contours) decreases, implying that waves are refracted more to the equator (see arrow), leading to decreases of $\operatorname{div} \mathbf{F}^{y} / \rho_{0}$ at the equatorward side of region II and increases of $\operatorname{div} \mathbf{F}^{y} / \rho_{0}$ at the poleward side of region II. Changes in $\operatorname{div} \mathbf{F}^{z} / \rho_{0}$ are related to changes in $F^{z}$ and, consequently, to changes in the vertical prop- (a)

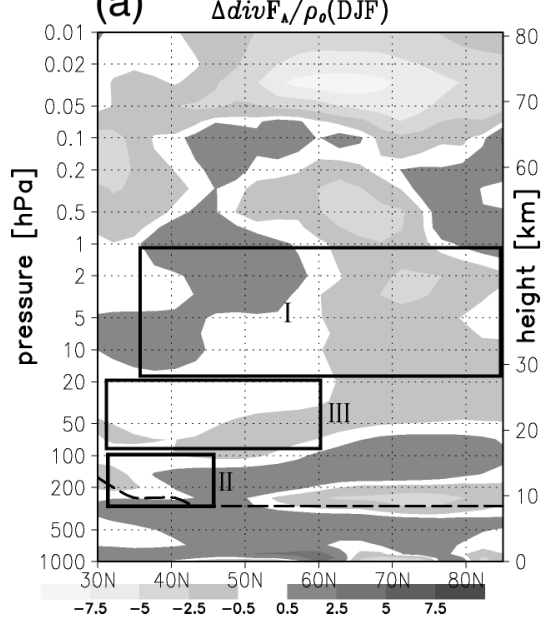

(b) $\Delta d i v \mathrm{~F}_{\alpha} / \rho_{0}, \Delta \mathrm{F}^{v_{A}}(\mathrm{DJF})$

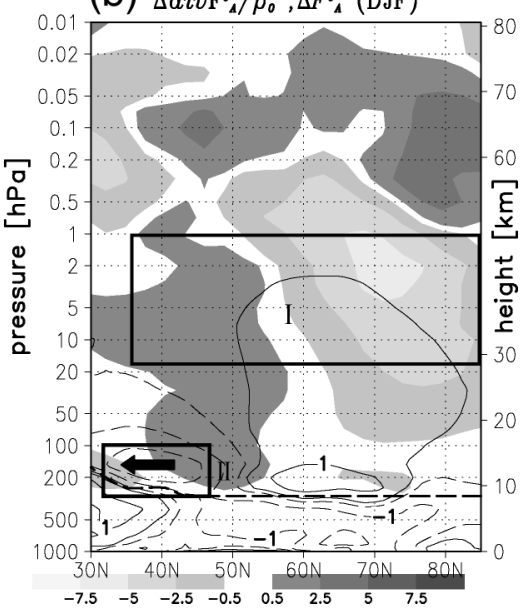

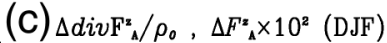

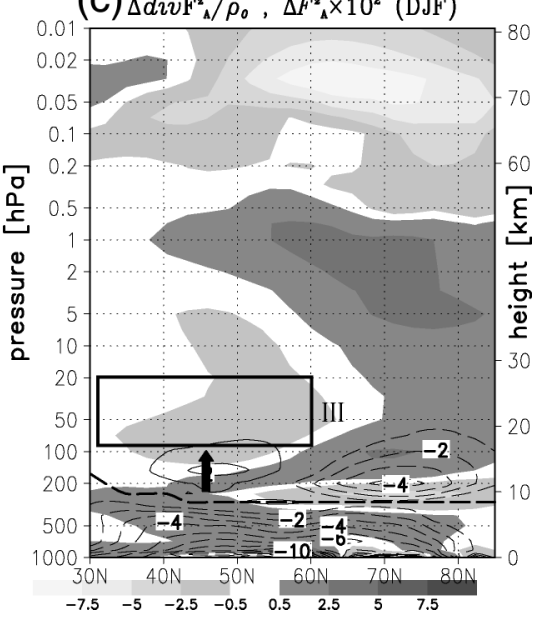

FIG. 4. The difference between the $\mathrm{A}$ and $\mathrm{C}$ runs in NH winter of (a) $\operatorname{div} \mathbf{F} / \rho_{0}$, (b) $\operatorname{div} \mathbf{F}^{y} / \rho_{0}$ (shaded) and $F^{y}$ (contours), (c) $\operatorname{div} \mathbf{F}^{z} / \rho_{0}(\operatorname{shaded})$ and $F^{z} \times 10^{2}$ (contours). See text for the meaning of the symbols. Here, $\operatorname{div} \mathbf{F} / \rho_{0}$ is in $\mathrm{m} \mathrm{s}^{-1} \mathrm{day}^{-1}$. The contour lines of $F^{y}$ are at \pm 0.2 , $\pm 1, \pm 2, \pm 3 \mathrm{~Pa}$, etc. and the contour interval of $F^{z}$ is $0.01 \mathrm{~Pa}$. The zero contour lines for both $F^{y}$ and $F^{z}$ are omitted. The arrows indicate the directions of the changes of the wave propagation discussed in the text. Only the NH extratropics are plotted. 
agation of the wave activity. Just below region III $F^{z}$ (Fig. 4c, contours) increases, which corresponds to more upward propagating wave activity (see upward arrow). This increased wave activity is dissipated in region III, causing a decrease of $\operatorname{div} \mathbf{F}^{z} / \rho_{0}$. In summary, the structure of $\Delta \operatorname{div} \mathbf{F}_{A} / \rho_{0}$ is mainly determined by changes in the meridional refraction of the wave activity in the $\mathrm{NH}$ upper stratosphere (region I) and in the NH subtropical lower stratosphere (region II), and by the increase of vertical wave activity in the $\mathrm{NH}$ midlatitude lower stratosphere (just below region III). Considering that the tropospheric vertical wave activity is decreased (see Fig. $4 \mathrm{c}$ ), the lower-stratospheric increase can have two causes: 1) the NH midlatitude tropopause is more "transparent" for tropospheric wave activity or 2) more wave activity is produced near the NH midlatitude tropopause.

The Arctic lower-stratospheric warming in response to $\mathrm{CO}_{2}$ increase (Fig. 2a) has been reported in several GCM studies (e.g., Rind et al. 1990, 1998, 2002; Mahfouf et al. 1994; Gillett et al. 2003). An exception is the study of Shindell et al. (1998) who report a cooling of the polar vortex [see Gillett et al. (2003) for a discussion]. Gillet et al. also found a weakening of the polar vortex whereas other studies (e.g., Rind et al. 1998; Shindell et al. 1998) found indications for a strengthening of the vortex. In the present study the Arctic lower-stratospheric warming is attributed to an increased residual circulation due to increased planetary and gravity wave driving. It should be noted that the change in the upward propagation of vertical wave energy quantified by $\Delta F_{A}^{z}$ at $100 \mathrm{hPa}$ was found to be largest in November, causing a huge deceleration of the polar vortex compared to the control run, and influencing the strength of the polar vortex in the succeeding winter. Thus, the strength of the DJF polar vortex is not only influenced by the DJF wave activity, but also by that in November. The increase of the NH midlatitude lower-stratospheric wave driving in $\mathrm{NH}$ winter is consistent to what has been found by, for example, Butchart and Scaife (2001) and Gillett et al. (2003). In the NH subtropical lower stratosphere, the increased wave driving is due to the equatorward refraction of wave activity, which is consistent with the results of, for example, Rind et al. (2002).

\section{c. The tropospheric response to uniform $\mathrm{CO}_{2}$ doubling}

Figure 2 a shows that the troposphere generally warms in response to a uniform $\mathrm{CO}_{2}$ doubling, with a maximum warming of more than $6 \mathrm{~K}$ in the tropical upper troposphere. Figure $2 \mathrm{~b}$ shows that the zonally averaged zonal wind in the tropospheric NH midlatitudes increases 0.5 to $1 \mathrm{~m} \mathrm{~s}^{-1}$. At the surface (Fig. 2d), these significant zonal wind increases are found in the storm track regions above the oceans. Above the northern Atlantic, the zonal wind increases more than $1.5 \mathrm{~m} \mathrm{~s}^{-1}$, which is about $20 \%$ of the zonal wind in the $\mathrm{C}$ run. The increase of the tropospheric NH midlatitude westerlies has been reported in several previous GCM studies (see section 1). The decrease of the zonal wind around $40^{\circ} \mathrm{S}$ and the increase around $60^{\circ} \mathrm{S}$ throughout the troposphere imply that the SH summer westerlies are shifted poleward. Figure 2e shows the surface air temperature change in response to a uniform $\mathrm{CO}_{2}$ doubling. It shows that the surface air temperature generally increases 2$3 \mathrm{~K}$, except at high latitudes, where the temperature increases up to $12 \mathrm{~K}$ due to the high-latitude warming amplification.

To summarize, the simulated uniformly doubled $\mathrm{CO}_{2}$ climate is characterized by a generally cooler middleatmosphere, an increased stratospheric residual circulation (caused by increased planetary and gravity wave driving) that is consistent with warmer temperatures in the Arctic lower stratosphere and a weakening of the zonal winds in the Arctic middle-atmosphere. Furthermore, the troposphere warms and the tropospheric NH midlatitude westerlies increase.

\section{The climate response to nonuniform $\mathrm{CO}_{2}$ doubling}

Experiments in which the $\mathrm{CO}_{2}$ is doubled nonuniformly (i.e., only in the troposphere or in the middleatmosphere) have been performed to study the mechanisms leading to the changes in the simulated uniformly doubled $\mathrm{CO}_{2}$ climate. Changes found in the uniformly doubled $\mathrm{CO}_{2}$ climate are attributed to either middleatmospheric or tropospheric $\mathrm{CO}_{2}$ doubling. This separation is only allowed when the responses are additive, that is, when the response to a uniform $\mathrm{CO}_{2}$ doubling can be regarded as the sum of the responses to $\mathrm{CO}_{2}$ doubling in the middle-atmosphere and in the troposphere. In other words, the following relationship should apply:

$$
\Delta Q_{A}=\Delta Q_{M}+\Delta Q_{T},
$$

where $\Delta Q_{X}$ is the response to $\mathrm{CO}_{2}$ doubling in region $\mathrm{X}$ (i.e., the difference between the $\mathrm{X}$ run and the $\mathrm{C}$ run) of the quantity $Q$. Relationship (5) will generally not be satisfied exactly due to nonlinear middle-atmosphere-troposphere interactions. It will be assumed that the responses are additive if relationship (5) applies at a more than $95 \%$ confidence level. A Student's $t$ test is applied to $\left(\Delta Q_{M}+\Delta Q_{T}-\Delta Q_{A}\right)$ to test whether this quantity significantly differs from zero. Significant nonadditives arise in regions where the value of $\left(\Delta Q_{M}+\right.$ $\Delta Q_{T}-\Delta Q_{A}$ ) is large or where its interannual variability is small.

\section{a. The middle-atmospheric response}

Figure 5 shows for $\mathrm{NH}$ winter the zonally averaged temperature response to middle-atmospheric $\mathrm{CO}_{2}$ doubling $\left(\Delta T_{M}\right.$, Fig. 5a) and to tropospheric $\mathrm{CO}_{2}$ doubling $\left(\Delta T_{T}\right.$, Fig. $\left.5 \mathrm{~b}\right)$. Figure $5 \mathrm{c}$ shows that the temperature 

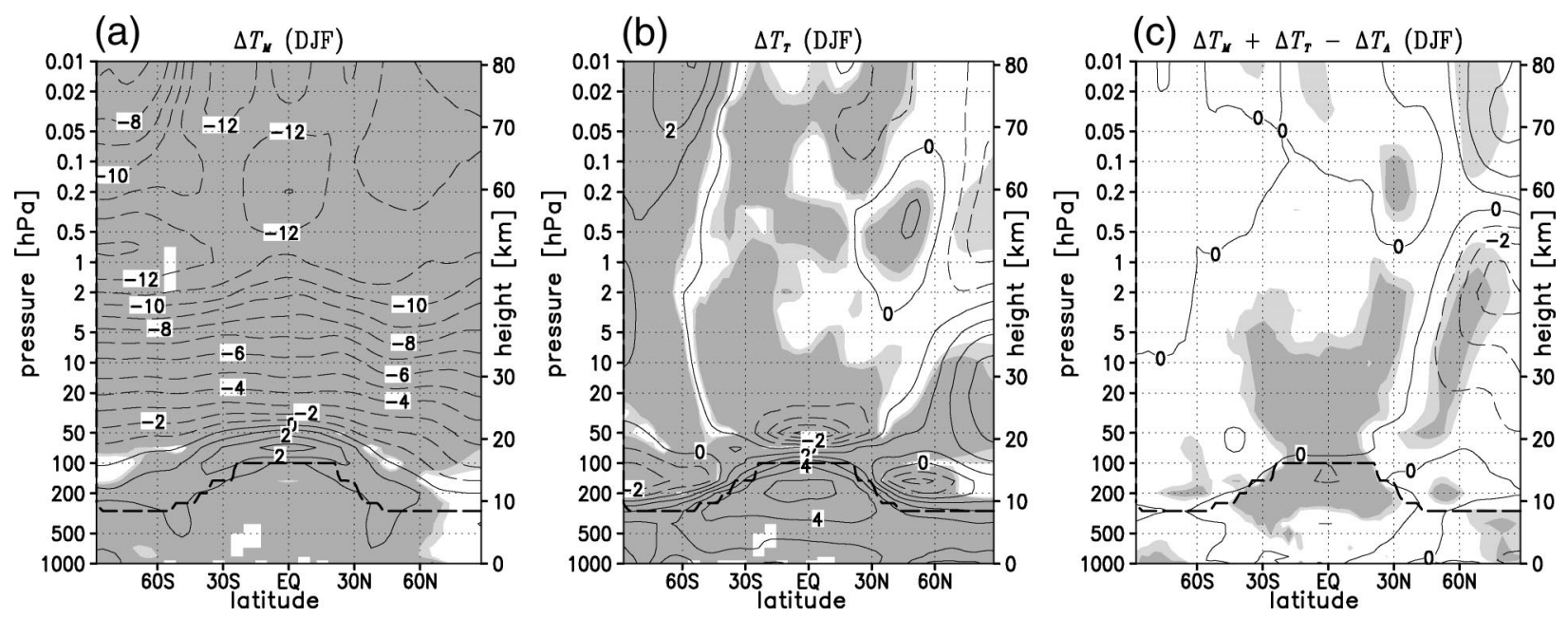

FIG. 5. The difference of the zonally averaged temperature between (a) the $\mathrm{M}$ and $\mathrm{C}$ runs and (b) the $\mathrm{T}$ and $\mathrm{C}$ runs for the DJF season. (c) The degree of nonadditivity of the temperature (i.e., $\Delta T_{M}+\Delta T_{T}-\Delta T_{A}$, see text). Light (dark) shading denotes significance at $95 \%$ (99\%) level of the changes in (a) and (b) and of the nonadditivity in (c). The contour interval is $1 \mathrm{~K}$. The bold dashed line denotes the position of the tropopause.

changes satisfy additiveness (i.e., $\Delta T_{M}+\Delta T_{T}-\Delta T_{A}$ $\approx 0$ ) in the largest part of the middle-atmosphere, except in some regions (shaded when not additive), which includes the tropical and part of the $\mathrm{NH}$ extratropical stratosphere. Note that the temperature responses are additive in the Arctic lower and middle stratosphere. Figure 6 shows the zonally averaged zonal wind response to middle-atmospheric $\mathrm{CO}_{2}$ doubling $\left(\Delta u_{M}\right.$, Fig. 6a) and to tropospheric $\mathrm{CO}_{2}$ doubling $\left(\Delta u_{T}\right.$, Fig. 6b) in $\mathrm{NH}$ winter. The shaded regions in Fig. 6c indicate regions where the zonal wind responses are not additive.

Figure $5 \mathrm{~b}$ shows that in the largest part of the middleatmosphere the temperature response to tropospheric $\mathrm{CO}_{2}$ doubling $\left(\Delta T_{T}\right)$ is small. This is not surprising considering that the $\mathrm{CO}_{2}$ concentration in the $\mathrm{T}$ run is not doubled in the middle-atmosphere so that direct ra- diative effects are absent. However, a statistically significant warming of more than $3 \mathrm{~K}$ in the Arctic lower stratosphere (maximum at $20 \mathrm{hPa}$ ) and a statistically significant cooling of more than $2 \mathrm{~K}$ in the tropical lower stratosphere (maximum at $50 \mathrm{hPa}$ ) is found. In the middle-atmosphere, $\Delta u_{T}$ is similar to $\Delta u_{A}$ (Fig. 2b): they both are positive in the Arctic and negative in the subtropics. Figure $7 \mathrm{~b}$ shows the change in the residual streamfunction in the T run. Similar to what was found in the $\mathrm{A}$ run, the residual circulation in the $\mathrm{T}$ run strengthens in most of the NH lower and middle stratosphere. However, different from what was found in the A run, the residual streamfunction does not increase in the NH upper stratosphere and mesosphere. The maximum of the NH residual streamfunction increases $18 \%$ at $50 \mathrm{hPa}$ and $26 \%$ at $100 \mathrm{hPa}$. These changes are ap-
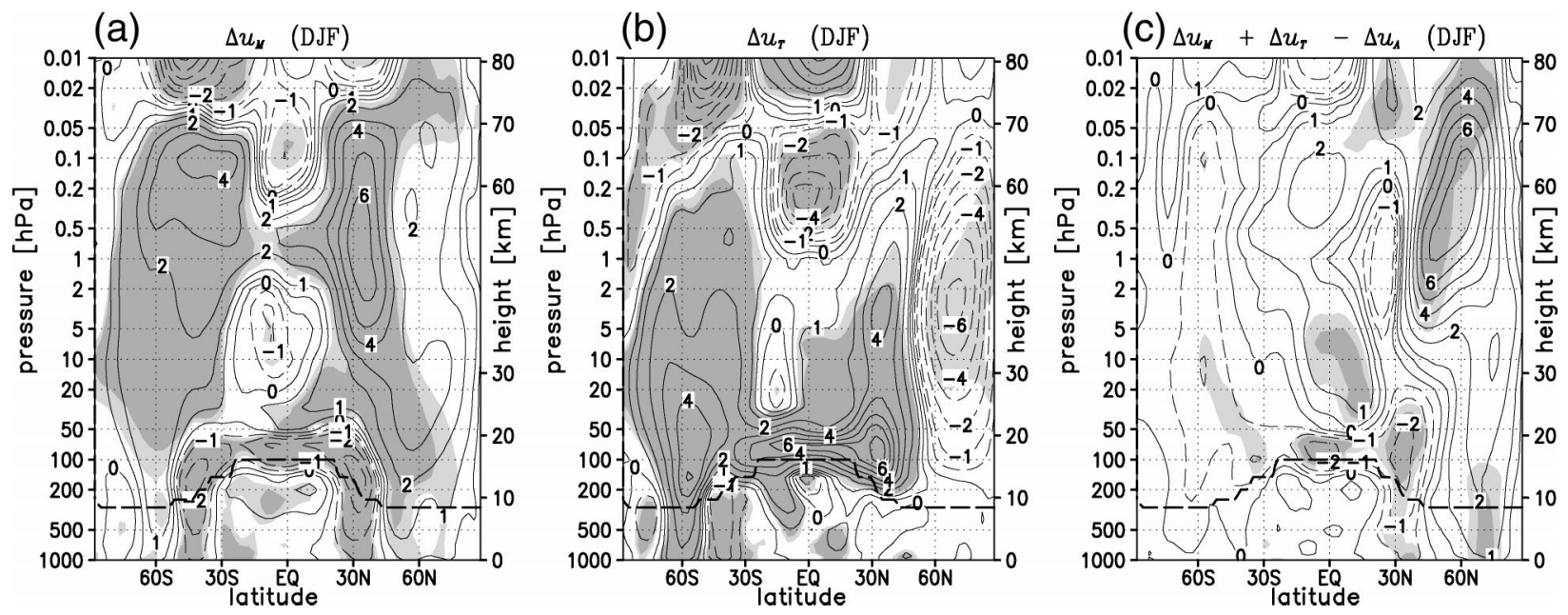

FIG. 6. As in Figs. 5a-c except for the zonally averaged zonal wind. The contour lines are at $0, \pm 0.5, \pm 1, \pm 2, \pm 3 \mathrm{~m} \mathrm{~s}^{-1}$, etc. Light (dark) shading denotes significance at $95 \%$ (99\%) level of the changes in (a) and (b) and of the nonadditivity in (c). 
(a)

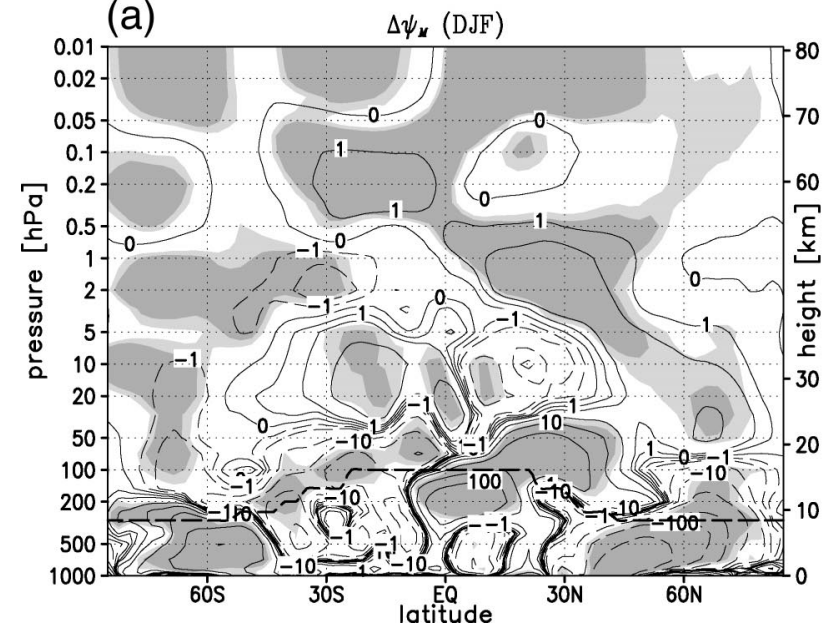

(b)

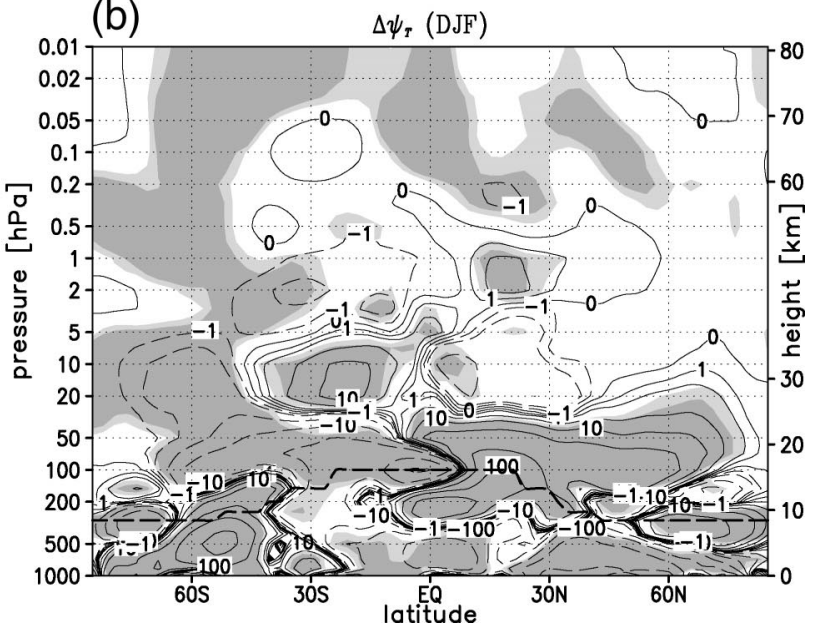

FIG. 7. As in Figs. 5a,b except for the residual streamfunction. Contour lines are at $0, \pm 1, \pm 2, \pm 5, \pm 10, \pm 20, \pm 50 \mathrm{~kg} \mathrm{~m}^{-1} \mathrm{~s}^{-1}$, etc. Light (dark) shading denotes significance at 95\% (99\%) level of the changes.

proximately two-thirds of the increases found in the A run. Associated with this increase, the downward motions near the North Pole increase too, leading to adiabatic heating and causing the temperature increase shown in Fig. 5b. Similarly, the upward motions in the tropical lower stratosphere increase, causing adiabatic cooling and a temperature decrease in the tropical lower stratosphere. Also similar to what was found in the A run, the increased extratropical stratospheric residual circulation is driven by the increased wave driving by both resolved (planetary) waves and unresolved (gravity) waves. The effect of the resolved waves on the zonal-mean flow is quantified by $\operatorname{div} \mathbf{F}_{T} / \rho_{0}$. The causes of $\Delta \operatorname{div} \mathbf{F}_{T} / \rho_{0}$ (Fig. 8b) are similar to the causes of $\Delta \operatorname{div} \mathbf{F}_{A} / \rho_{0}$ described in section $3 \mathrm{~b}$ : the negative values of $\Delta \operatorname{div} \mathbf{F}_{T} / \rho_{0}$ in the NH midlatitude lower stratosphere are again mainly caused by dissipation of increased upward propagating wave activity in the lower strato- sphere, and the pattern of $\Delta \operatorname{div} \mathbf{F}_{T} / \rho_{0}$ in the NH subtropical lower stratosphere and in the $\mathrm{NH}$ upper stratosphere is again mainly determined by changes in the meridional refraction of the planetary waves (not shown). To summarize, the patterns and causes of the middle-atmospheric changes in the $\mathrm{T}$ run are similar to those in the A run, with the exception that in the $\mathrm{T}$ run the middle-atmosphere does not cool due to the radiative effects of $\mathrm{CO}_{2}$ doubling. The residual circulation increase in the T run is about two-thirds of the increase in the A run.

Figure 5a shows that the middle-atmosphere cools in response to middle-atmospheric $\mathrm{CO}_{2}$ doubling, which can be explained by radiative arguments. Since the temperature responses in the Arctic lower stratosphere are additive (Fig. 5c), it is tempting to conclude that the positive $\Delta T_{A}$ in the Arctic stratosphere (Fig. 2a) is a small residual of a negative $\Delta T_{M}$ due to radiative cooling
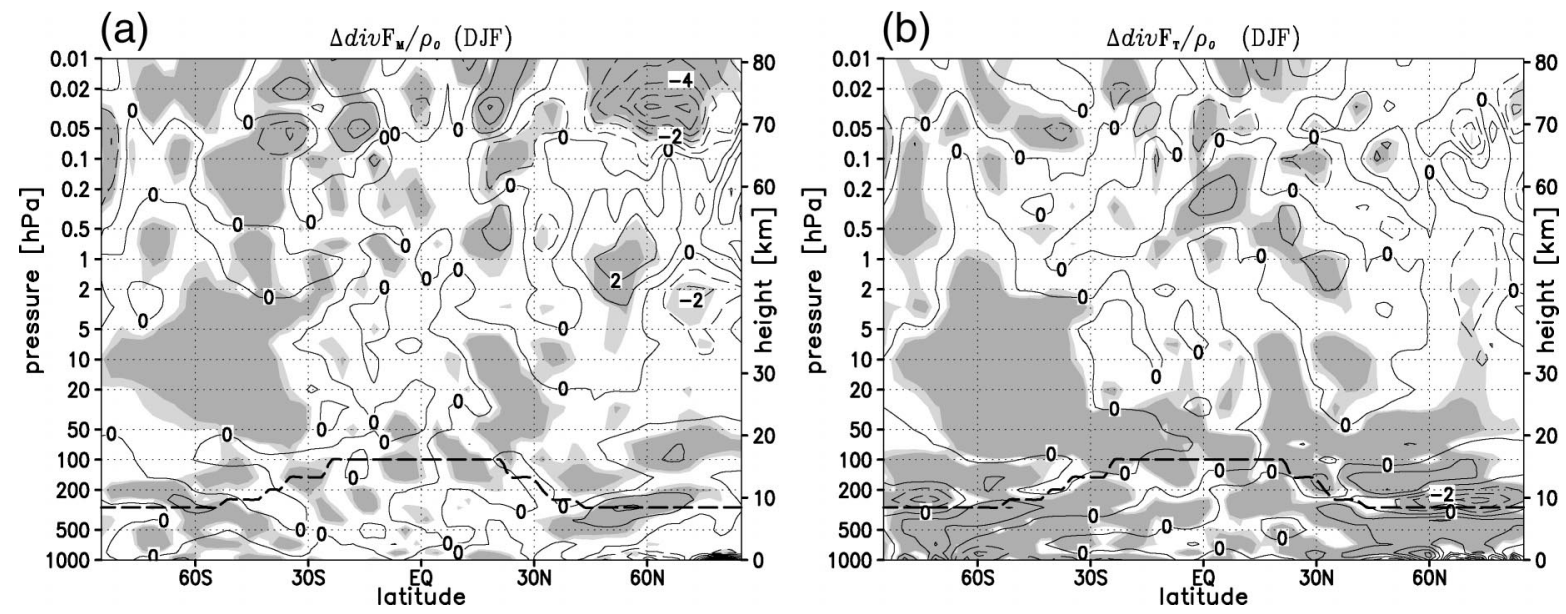

FIG. 8. As in Figs. 5a,b except for $\operatorname{div} \mathbf{F} / \rho_{0}$. The contour interval is $1 \mathrm{~m} \mathrm{~s}^{-1}$ day $^{-1}$. Light (dark) shading denotes significance at $95 \%$ $(99 \%)$ level of the changes. 
(a)

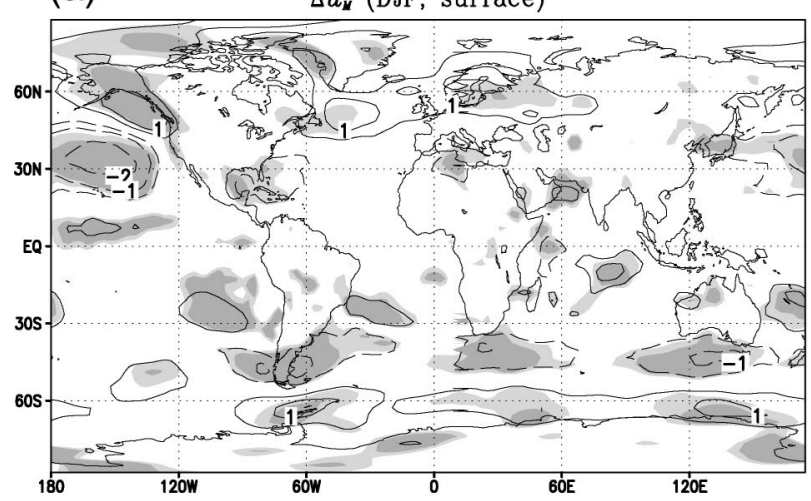

(b)

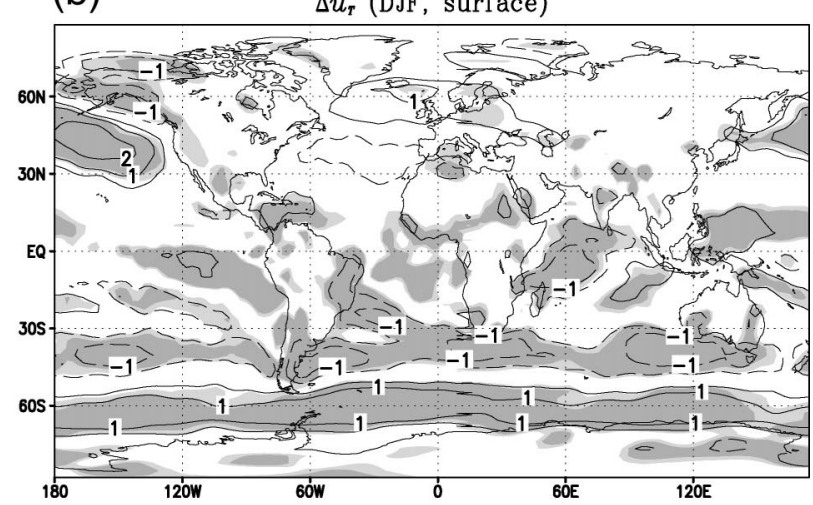

\section{(c)}

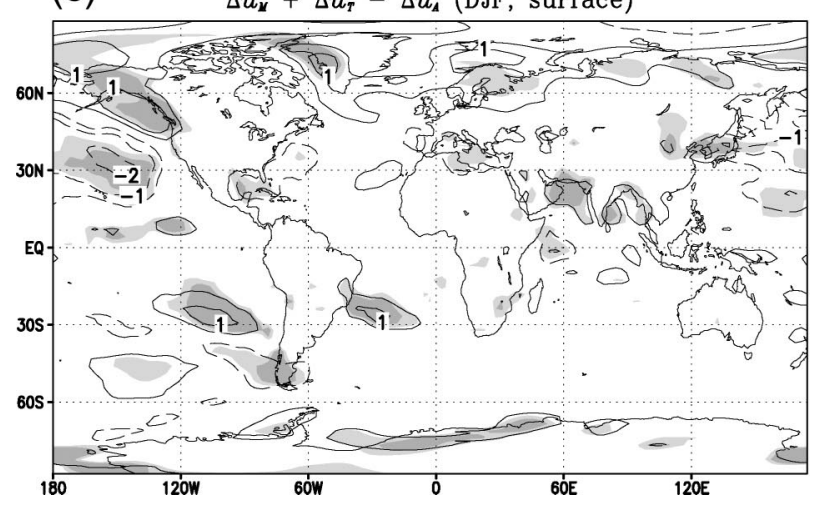

and a somewhat larger positive $\Delta T_{T}$ due to dynamical heating. However, a more detailed investigation of the responses in the $\mathrm{M}$ run reveals that $\Delta T_{M}$ itself is a result of both radiative cooling and dynamical heating. Figure 7a shows that, similar to what was found in the A run, the stratospheric residual circulation in the $\mathrm{M}$ run generally increases, with the exception of the tropical middle stratosphere. The amplitude of this increase is approximately one-third of that in the A run; the maximum of the residual streamfunction in the $\mathrm{M}$ run increases $7 \%$ at $50 \mathrm{hPa}$ and $13 \%$ at $100 \mathrm{hPa}$. Similar to what was found in the $\mathrm{A}$ and the T runs, this increase is associated with stronger downward motions in and a warming of the Arctic lower stratosphere. Since $\Delta T_{M}$ is negative in this region, it can be concluded that in the $\mathrm{M}$ run the radiative cooling is larger than the dynamical heating. The patterns of $\Delta \operatorname{div} \mathbf{F}_{M} / \rho_{0}$ (Fig. 8a), $\Delta \operatorname{div} \mathbf{F}_{M}^{y} / \rho_{0}$ and $\Delta \operatorname{div} \mathbf{F}_{M}^{z} / \rho_{0}$ (not shown) are similar to those in the $\mathrm{T}$ and A runs, but the amplitudes are smaller.

In summary, the simulated Arctic lower stratospheric warming in the uniformly doubled $\mathrm{CO}_{2}$ climate is a small residual of radiative cooling and dynamical heating. The dynamical heating is caused by increased downward motions associated with the increase of the stratospheric residual circulation, which is caused by
FIG. 9. As in Figs. 5a-c except for the surface zonal wind. The contour lines are at $\pm 0.5, \pm 1, \pm 2, \pm 3 \mathrm{~m} \mathrm{~s}^{-1}$, etc., and the zero contour line has been omitted. Light (dark) shading denotes significance at $95 \%$ (99\%) level of the changes in (a) and (b) and of the nonadditivity in (c).

the increase of both the resolved and unresolved wave driving. The stratospheric residual circulation increase can be attributed for about two-thirds to the (remote) tropospheric $\mathrm{CO}_{2}$ doubling and for about one-third to the (in situ) middle-atmospheric $\mathrm{CO}_{2}$ doubling.

\section{b. The tropospheric and surface-level response}

Figure $5 \mathrm{c}$ shows that the tropospheric temperature changes satisfy additiveness in most regions, except in the tropical upper troposphere and the polar troposphere. Figure $6 \mathrm{c}$ shows that the tropospheric zonal wind changes satisfy additiveness in most regions, including the $\mathrm{NH}$ midlatitudes. Figure 9 shows the zonal wind responses at the surface. Figure $9 \mathrm{c}$ shows that the surface zonal wind responses are additive above the entire northern Atlantic. In this region, both $\Delta u_{M}$ (Fig. 9a) and $\Delta u_{T}$ (Fig. 9b) are positive. The zonal wind responses are not additive in large parts of the northern Pacific. In this region, the pattern of $\Delta u_{T}$ is similar to that of $\Delta u_{A}$, whereas the pattern of $\Delta u_{M}$ is completely different. In the midlatitudes of the Southern Hemisphere the zonal wind responses are additive, and the patterns of both $\Delta u_{M}$ and $\Delta u_{T}$ are similar to that of $\Delta u_{A}$.

Figure 5a shows that in the largest part of the tro- 
posphere the temperature response to middle-atmospheric $\mathrm{CO}_{2}$ doubling $\left(\Delta T_{M}\right)$ is small. This is not surprising since in the $\mathrm{M}$ run the $\mathrm{CO}_{2}$ is not doubled in the troposphere, so direct radiative effects are absent. The tropospheric $\Delta T_{M}$ is characterized by a "tongue" of increased positive $\Delta T_{M}$ in both the $\mathrm{NH}$ and $\mathrm{SH}$ midlatitudes. In the NH midlatitudes $\Delta u_{M}$ (Fig. 6a) is similar to $\Delta u_{A}$. The tropospheric $u_{M}$ increases in the region north of $45^{\circ} \mathrm{N}$. This increase is largest around $55^{\circ} \mathrm{N}$ and is generally statistically significant between $45^{\circ}$ and $70^{\circ} \mathrm{N}$. The amplitude of $\Delta u_{M}$ is here comparable to that of $\Delta u_{A}$, implying that this tropospheric zonal wind response to middle-atmospheric $\mathrm{CO}_{2}$ doubling is substantial. Since the zonal wind responses are nonadditive in the regions around $35^{\circ}$ and $70^{\circ} \mathrm{N}$, the negative $\Delta u_{M}$ near $35^{\circ} \mathrm{N}$ and the positive $\Delta u_{M}$ north of $65^{\circ} \mathrm{N}$ will not be further discussed. The poleward shift of the SH westerlies in the A run also occurs in the $\mathrm{M}$ run. In this region, $\Delta u_{M}$ is about one-third of $\Delta u_{A}$. Figure 9a shows the surface zonal wind response to middle-atmospheric $\mathrm{CO}_{2}$ doubling. The positive $\Delta u_{M}$ in the western part of the northern Atlantic is statistically significant, and only slightly smaller than $\Delta u_{A}$ (Fig. 2d). Since the surface zonal wind responses were shown to be nonadditive above the northern Pacific (Fig. 9c), the pattern of $\Delta u_{M}$ in this region will not be discussed. The surface air temperature change in the $\mathrm{M}$ run (not shown) is generally smaller than $1 \mathrm{~K}$. No high-latitude warming amplification is found because the sea ice distribution of the control run has been used.

Figure $5 \mathrm{~b}$ shows that the troposphere warms in response to tropospheric $\mathrm{CO}_{2}$ doubling, which is due to the radiative effects of the increased $\mathrm{CO}_{2}$ concentration. In the troposphere, $\Delta T_{T}$ is about $80 \%$ of $\Delta T_{A}$. Since the imposed SST increases in the T run are $84 \%$ of those in the A run (see section 2), this result suggests that the strength of the tropospheric warming is also influenced by the imposed SSTs. The structure of $\Delta T_{T}$ is similar to that of $\Delta T_{A}$ : the largest values (more than $5 \mathrm{~K}$ ) occur in the tropical upper troposphere. In the NH midlatitude troposphere $\Delta u_{T}$ (Fig. 6b) is very small and not statistically significant, in contrast to $\Delta u_{M}$ (Fig. 6a). Since the zonal wind responses are additive in this region, this result indicates that not the tropospheric $\mathrm{CO}_{2}$ doubling, but the remote middle-atmospheric $\mathrm{CO}_{2}$ doubling is the main cause of the increased tropospheric $\mathrm{NH}$ midlatitude westerlies in the uniformly doubled $\mathrm{CO}_{2}$ climate. It indicates that the downward influence of the middleatmospheric $\mathrm{CO}_{2}$ increase on the tropospheric climate is quite pronounced, at least in the $\mathrm{NH}$ midlatitudes. Figure $6 \mathrm{~b}$ shows that the poleward shift of the $\mathrm{SH}$ westerlies also occurs in the $\mathrm{T}$ run. In this region, the amplitude of $\Delta u_{T}$ is about two-thirds of that of $\Delta u_{A}$. As the zonal wind responses are additive in this region, this suggests that the poleward shift of the $\mathrm{SH}$ westerlies in the uniformly doubled $\mathrm{CO}_{2}$ climate is mainly due to tropospheric $\mathrm{CO}_{2}$ doubling. In contrast to the tropospheric zonal mean $\Delta u_{T}$, the surface $\Delta u_{T}$ (Fig. 9b) is statistically significant in some parts of the NH midlatitudes. The surface zonal wind above the northern Atlantic increases in response to tropospheric $\mathrm{CO}_{2}$ doubling, but this increase is only significant in a small region in the east part of the northern Atlantic. The pattern of the surface air temperature change in the $\mathrm{T}$ run (not shown) is very similar to that in the A run (Fig. 2e). The high-latitude warming amplification is also found in the $\mathrm{T}$ run because the sea ice distribution of the A run has been used.

To summarize, the middle-atmospheric $\mathrm{CO}_{2}$ doubling causes significant increases in the tropospheric $\mathrm{NH}$ midlatitude westerlies, in contrast to the tropospheric $\mathrm{CO}_{2}$ doubling. Since the zonal wind responses are additive in this region, it can be concluded that the middle-atmospheric $\mathrm{CO}_{2}$ doubling is the main cause of the increased tropospheric $\mathrm{NH}$ midlatitude westerlies in the uniformly doubled $\mathrm{CO}_{2}$ climate.

\section{Additional experiments on the response of the troposphere to middle-atmospheric $\mathrm{CO}_{2}$ doubling}

In section $4 \mathrm{~b}$ it has been shown with the $\mathrm{M}$ run that the middle-atmospheric $\mathrm{CO}_{2}$ doubling causes significant increases in the tropospheric NH midlatitude westerlies during DJF. To account for the effect of the radiative forcing of middle-atmospheric $\mathrm{CO}_{2}$ doubling on the SSTs, the imposed SST increase in the $\mathrm{M}$ run is $16 \%$ of that in the A run (see section $2 b$ ).

Two questions arise that will be addressed in this section:

1) Which part of the tropospheric response in the Mrun is caused by the imposed SST changes, and which part is caused by the middle-atmospheric $\mathrm{CO}_{2}$ doubling?

2) How well should the middle-atmosphere be represented in GCMs to capture the middle-atmospheric influence on the troposphere?

The first question will be addressed in section $5 \mathrm{a}$, where results will be presented from an experiment (denoted as the MC run) with the same configurations as the $\mathrm{M}$ run, except that the control SSTs are prescribed. The second question will be addressed in section $5 \mathrm{~b}$, where results will be presented from an experiment in which the $\mathrm{CO}_{2}$ is doubled only above $10 \mathrm{hPa}$. The responses found in this experiment will give an indication of how much of the middle-atmospheric $\mathrm{CO}_{2}$ doubling influence on the troposphere is not captured in GCMs with an upper boundary around $10 \mathrm{hPa}$.

\section{a. The tropospheric response to middle-atmospheric $\mathrm{CO}_{2}$ doubling without change of SSTs}

Figure 10a shows that the tropospheric pattern of the temperature response in the $\mathrm{MC}$ run (denoted as $\Delta T_{\mathrm{MC}}$ ) is similar to that in the M run (Fig. 5a) in the Northern 

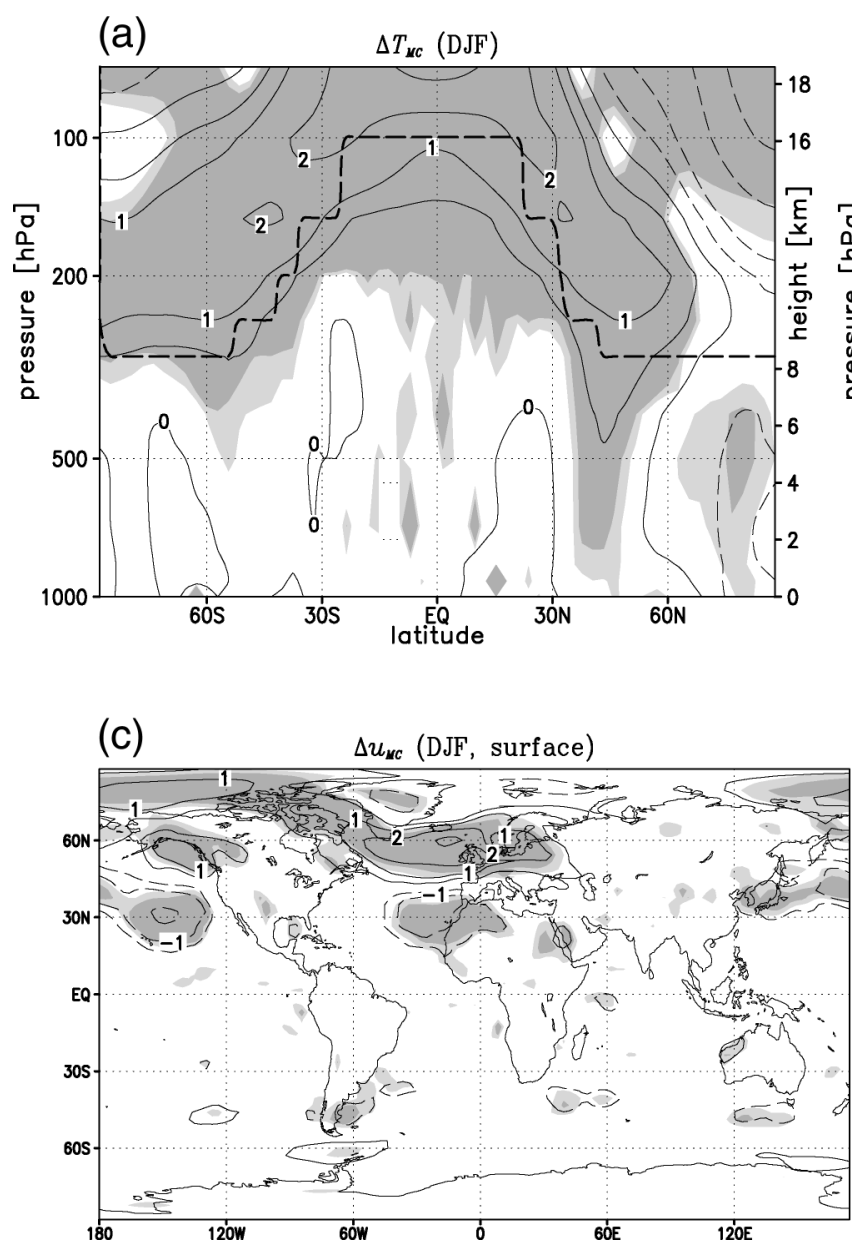

(b)

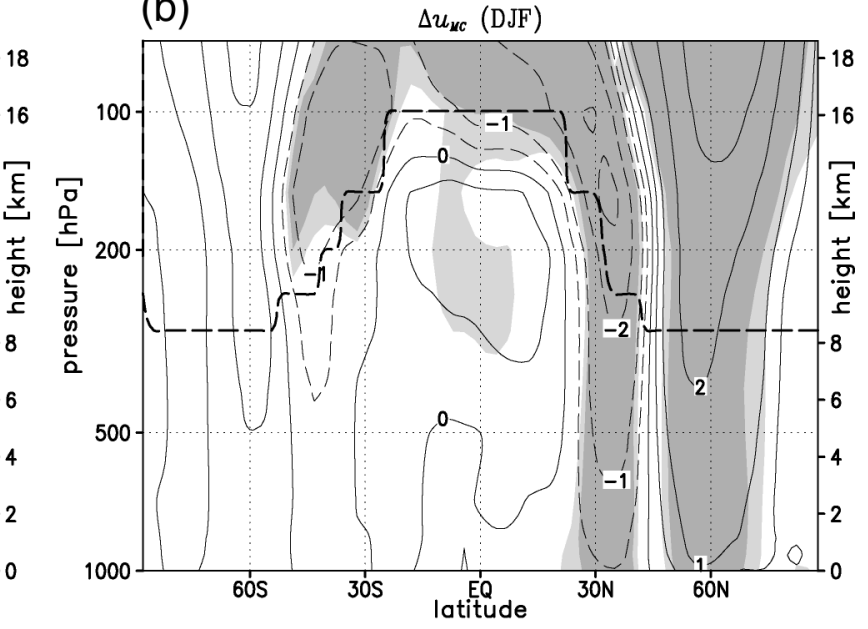

FIG. 10. The difference of the zonally averaged (a) temperature, (b) zonal wind, and (c) the surface zonal wind between the MC and $\mathrm{C}$ runs in the DJF season. The contour lines in Fig. 10a are at $0, \pm 0.5, \pm 1, \pm 2, \pm 3 \mathrm{~K}$, etc. Contour lines in (b), (c) are the same as in Figs. 2b,d. Light (dark) shading denotes significance of the changes at $95 \%(99 \%)$ level.
Hemisphere, but different from that in the $\mathrm{M}$ run in the Southern Hemisphere: in the MC run the tongue of increased temperatures is only found in the Northern Hemisphere. The $\Delta T_{\mathrm{MC}}$ is $0.3-1 \mathrm{~K}$ smaller than $\Delta T_{M}$. These results show that the imposed SST changes in the $\mathrm{M}$ run cause a rather uniform tropospheric warming and a tongue of additional warming in the $\mathrm{SH}$ midlatitudes. Similar conclusions can be drawn for the tropospheric zonal wind (Fig. 10b): the significant midlatitude zonal wind increases in the $\mathrm{M}$ run only occur in the $\mathrm{MC}$ run in the midlatitudes of the Northern Hemisphere. The tropospheric $\Delta u_{\mathrm{MC}}$ is even larger than the $\Delta u_{M}$, suggesting that in the $M$ run the imposed SSTs weaken the tropospheric zonal wind response to middle-atmospheric $\mathrm{CO}_{2}$ doubling. Similar results are found for the surface zonal wind: above the northern Atlantic the surface $\Delta u_{\mathrm{MC}}$ (Fig. 10c) is about twice larger than the surface $\Delta u_{M}$. It can thus be concluded that, in the $\mathrm{M}$ run, the increased $\mathrm{NH}$ westerlies are not caused by the imposed SSTs, but by the middle-atmospheric $\mathrm{CO}_{2}$ doubling. From this result and the results presented in section $4 \mathrm{~b}$, it can be concluded that the middle-atmospheric $\mathrm{CO}_{2}$ doubling and not the imposed SSTs or tropospheric $\mathrm{CO}_{2}$ doubling is the main cause of the increased $\mathrm{NH}$ west- erlies in the uniformly doubled $\mathrm{CO}_{2}$ climate. On the other hand, the poleward shift of the $\mathrm{SH}$ westerlies in the $M$ run is not found in the MC run, suggesting that the $\mathrm{SH}$ response in the $\mathrm{M}$ run is caused by the imposed SST changes. It is concluded that not the middle-atmospheric $\mathrm{CO}_{2}$ doubling, but the tropospheric $\mathrm{CO}_{2}$ doubling and the imposed SSTs cause the poleward shift of the $\mathrm{SH}$ midlatitude westerlies in the uniformly doubled $\mathrm{CO}_{2}$ climate.

\section{b. The tropospheric response to $\mathrm{CO}_{2}$ doubling above $10 \mathrm{hPa}$}

Now that it has been demonstrated that the middleatmospheric $\mathrm{CO}_{2}$ doubling is important for the tropospheric and surface climate response in the uniformly doubled $\mathrm{CO}_{2}$ climate, one may wonder how well the middle-atmosphere has to be represented in GCMs to capture this downward influence. As described in section 1, several authors have addressed the issue of how high the model top should be to produce realistic climate simulations. Gillett et al. (2002) and Shindell et al. (1999) compared the AO responses to increasing greenhouse gases in a high (upper boundary around $0.01 \mathrm{hPa}$ ) 
(a)

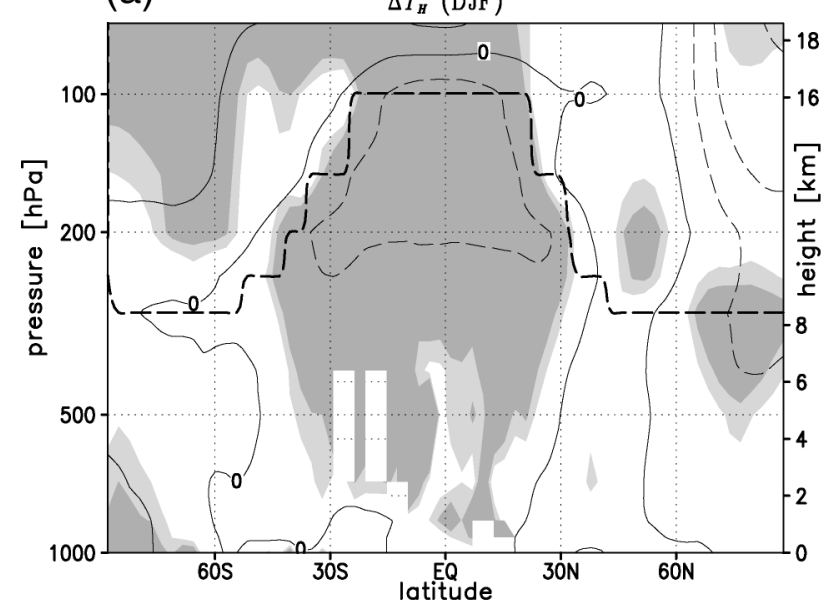

(c)

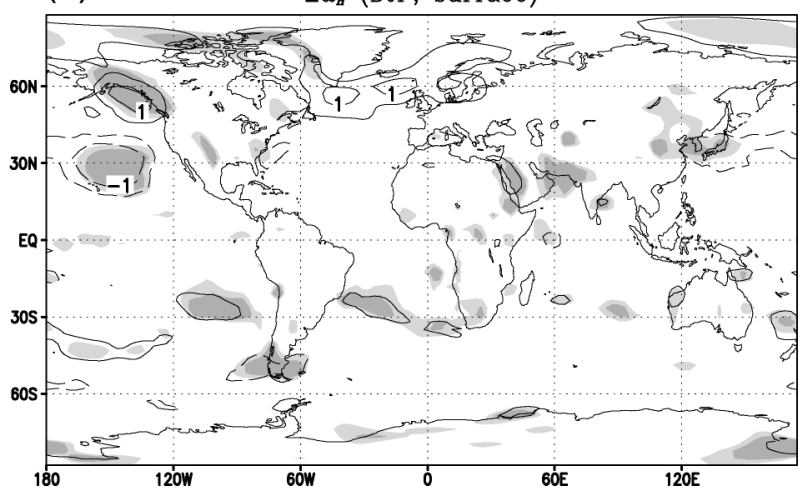

(b)

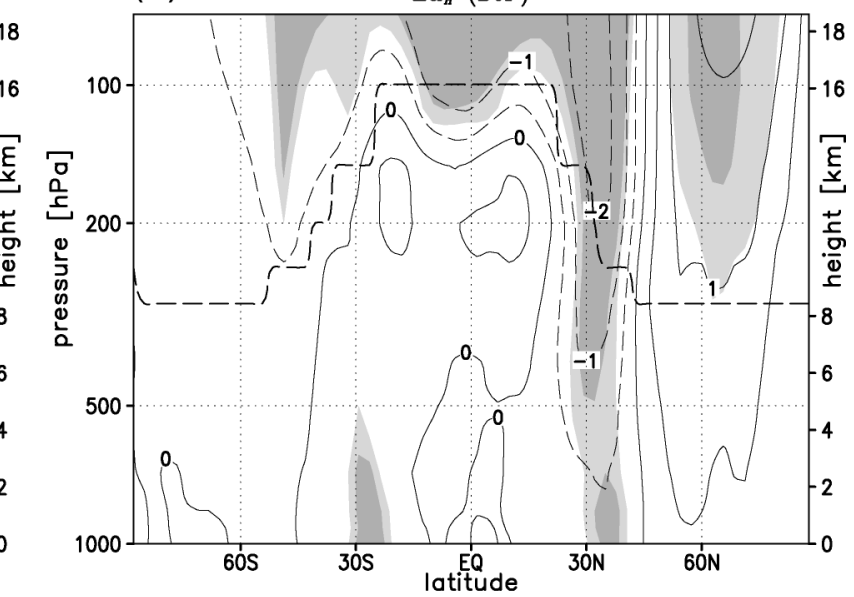

FIG. 11. As in Figs. 10a-c except for the difference between the $\mathrm{H}$ and $\mathrm{C}$ runs. Light (dark) shading denotes significance of the changes at $95 \%(99 \%)$ level. and a low (upper boundary around $10 \mathrm{hPa}$ ) version of their models, and found contrasting results. Rind et al. (1998) also addressed the model top question and found that the stratospheric responses to doubled $\mathrm{CO}_{2}$ in models with model tops at 0.01 and $1 \mathrm{hPa}$ are similar. Instead of investigating the required minimum model top height for producing reliable climate predictions, here we address a slightly different issue. An additional run has been performed in which the $\mathrm{CO}_{2}$ is doubled between 10 and $0.01 \mathrm{hPa}$ to investigate directly the influence of $\mathrm{CO}_{2}$ changes above $10 \mathrm{hPa}$ on the surface climate. SSTs from the control run are imposed in this run, which will be referred to as the $\mathrm{H}$ run.

Figure 11a shows that the tropospheric temperature response to $\mathrm{CO}_{2}$ doubling above $10 \mathrm{hPa}\left(\Delta T_{H}\right)$ is generally small. The tropospheric zonal wind response in the $\mathrm{NH}$ midlatitudes $\left(\Delta u_{H}\right.$, Fig. $\left.11 \mathrm{~b}\right)$ is surprisingly large: $\Delta u_{H}$ is not much smaller than $\Delta u_{M}$ (Fig. 6a) and about $50 \%$ of $\Delta u_{\mathrm{MC}}$ (Fig. 10b). As in the $\mathrm{M}$ and $\mathrm{MC}$ runs, the zonal wind decreases significantly around $35^{\circ} \mathrm{N}$. The zonal wind in the $\mathrm{SH}$ troposphere does not change significantly in the $\mathrm{H}$ run. The structure of the surface $\Delta u_{H}$ is again similar to that of $\Delta u_{\mathrm{MC}}$ (Fig. 10c) and $\Delta u_{M}$ (Fig. 9a), whereas the amplitude is slightly smaller than the amplitude of $\Delta u_{M}$ and about $50 \%$ of the amplitude of $\Delta u_{\mathrm{MC}}$. These results suggest that $\mathrm{CO}_{2}$ doubling above $10 \mathrm{hPa}$ significantly contributes to the strengthening of the tropospheric $\mathrm{NH}$ midlatitude westerlies in the uniformly doubled $\mathrm{CO}_{2}$ climate.

\section{Discussion and conclusions}

In this paper, the separate climate effects during $\mathrm{NH}$ winter of tropospheric and middle-atmospheric $\mathrm{CO}_{2}$ doubling have been studied with the middle-atmosphere version of the ECHAM global climate model. It has been investigated to what extent the changes in the uniformly doubled $\mathrm{CO}_{2}$ climate can be considered as the sum of the separate tropospheric and middle-atmospheric $\mathrm{CO}_{2}$ doubling responses. Thereafter, changes in the uniformly doubled $\mathrm{CO}_{2}$ climate have been attributed to either tropospheric or middle-atmospheric $\mathrm{CO}_{2}$ doubling. In addition, the question of how well the middleatmosphere has to be represented in GCMs to acquire reliable tropospheric climate predictions has been addressed.

Since planetary waves originating from the troposphere are dissipated in the stratosphere and drive a 
meridional circulation and the stratosphere is thought to exert a significant downward influence on the troposphere, the coupling between the middle-atmosphere and the troposphere is anticipated to be important for understanding the changes in the doubled $\mathrm{CO}_{2}$ climate (section 1). In the doubled $\mathrm{CO}_{2}$ climate the Arctic lower stratosphere slightly warms, causing a decrease of the meridional temperature gradient and, consequently, a weakening of the Arctic middle-atmospheric zonal wind (section 3). The small warming is thought to be caused by increased downward motions associated with an increased residual circulation. In the Arctic lower stratosphere the temperature response in the uniformly doubled $\mathrm{CO}_{2}$ climate can be regarded as the sum of the responses to $\mathrm{CO}_{2}$ doubling in the middle-atmosphere and in the troposphere. The increased residual circulation contributing to the small Arctic lower stratospheric warming in the uniformly doubled $\mathrm{CO}_{2}$ climate can be attributed for about two-thirds to the tropospheric $\mathrm{CO}_{2}$ doubling and about one-third to the middle-atmospheric $\mathrm{CO}_{2}$ doubling (section 4a). These results are consistent with those presented by Rind et al. (1990), who with much shorter experiments found that both middle-atmospheric and tropospheric $\mathrm{CO}_{2}$ doubling contribute to the increase of the residual circulation. However, the increase of the stratospheric residual circulation and the resulting dynamical heating due to "in situ" middleatmospheric $\mathrm{CO}_{2}$ doubling is probably larger in their study. In their STRAT run, which can be compared to our M run, the dynamical heating due to the stratospheric residual circulation increase exceeds the radiative cooling, resulting in an upper-stratospheric warming (their Fig. 4). In our M run the dynamical heating is smaller than the radiative cooling, resulting in a cooling in the entire middle-atmosphere (Fig. 5a). However, the STRAT run was integrated for one winter, whereas our $\mathrm{M}$ run was integrated for 30 years. Therefore, the different results may be due to model differences, but also due to differences in the length of the integration.

In the uniformly doubled $\mathrm{CO}_{2}$ climate the tropospheric NH midlatitude westerlies increase and the SH westerlies shift poleward (section 3 ). The zonal wind responses were shown to be additive in these regions. The increased tropospheric NH midlatitudes westerlies are mainly caused by the (remote) middle-atmospheric $\mathrm{CO}_{2}$ doubling and not by the tropospheric $\mathrm{CO}_{2}$ doubling (section 4b). The middle-atmosphere contains only $\sim 15 \%$ of the total atmospheric mass. If we consider the zonal wind response in terms of response per $\mathrm{kg} \mathrm{CO}_{2}$ increase, the zonal wind response to middle-atmospheric $\mathrm{CO}_{2}$ doubling is even more dominant over that due to tropospheric $\mathrm{CO}_{2}$ doubling. In contrast, the poleward shift of the $\mathrm{SH}$ tropospheric westerlies has been attributed to the tropospheric $\mathrm{CO}_{2}$ doubling.

It has been concluded that in $\mathrm{NH}$ winter the middleatmospheric $\mathrm{CO}_{2}$ doubling has an important effect on the $\mathrm{NH}$ tropospheric climate change. The question of how well the middle-atmosphere has to be represented in GCMs to capture this downward influence has been addressed in section $5 \mathrm{~b}$. It has been shown that $\mathrm{CO}_{2}$ doubling above $10 \mathrm{hPa}$ already causes significant increases of the tropospheric NH midlatitude westerlies.

The question of which mechanisms are responsible for the downward influence of the middle-atmosphere in the doubled $\mathrm{CO}_{2}$ climate is still under debate. Shindell et al. (1999) argue that the change in the meridional temperature gradient in the midlatitude tropopause region in response to increasing greenhouse gases causes changes in the stratospheric circulation that could influence the tropospheric circulation through wave-mean flow interactions. The attribution of the tropospheric $\mathrm{NH}$ midlatitude zonal wind increase to middle-atmospheric $\mathrm{CO}_{2}$ doubling, and the attribution of the poleward shift of the tropospheric $\mathrm{SH}$ summer westerlies to tropospheric $\mathrm{CO}_{2}$ doubling are consistent with this hypothesis. The middle-atmospheric zonal wind in $\mathrm{NH}$ winter is easterly in the $\mathrm{SH}$, constituting a barrier for the transport of tropospheric wave activity into the middle-atmosphere (Charney and Drazin 1961). Because of the lack of wave activity in the middle-atmosphere, the middle-atmosphere cannot influence the tropospheric climate through wave-mean flow interactions. Therefore, the changes in the $\mathrm{SH}$ summer troposphere in the doubled $\mathrm{CO}_{2}$ climate are expected to be the result of changes in the troposphere itself, and not from the coupling with the middle-atmosphere. In the Northern Hemisphere winter, the NH middle-atmospheric zonal wind is westerly, allowing tropospheric wave activity to propagate into the stratosphere, which, through wave-mean flow interactions can influence the troposphere. Shindell et al. (1999) found a strengthening of the Arctic vortex in response to increasing greenhouse gases and argued that it induces a strengthening of the (lower) tropospheric westerlies through wave-mean flow interactions. Our results do not support this argument since we also find a strengthening of the tropospheric $\mathrm{NH}$ midlatitude westerlies, but a weakening of the stratospheric Arctic zonal winds [both results are also found in other models, see Gillett et al. (2003)]. This does not contradict the hypothesis that the tropospheric NH midlatitude zonal wind changes are induced by stratospheric zonal wind changes through wave-mean flow interactions, but the exact mechanism remains unclear.

In summary, in this paper the importance of the tropospheric climate change for the increase of the stratospheric residual circulation and associated middle-atmospheric responses (small Arctic lower stratospheric warming and weakening of zonal wind in the Arctic middle-atmosphere) in the uniformly doubled $\mathrm{CO}_{2}$ climate has been shown. In addition, the results indicate the crucial role of the middle-atmospheric climate change in the increase of the tropospheric NH midlatitude westerlies in the uniformly doubled $\mathrm{CO}_{2}$ climate. Finally, the need to include the region above $10 \mathrm{hPa}$ in GCMs to acquire realistic climate predictions has been advocated. 
Acknowledgments. The authors would like to thank Hans Cuijpers (KNMI) for extensive model support, Peter van Velthoven and Rob van Dorland (both KNMI), Frans Sluijter (Eindhoven University of Technology), and Neal Butchart and Adam Scaife (both U.K. Meteorological Office) for helpful comments and suggestions, Kleareti Tourpali (University of Thessaloniki) for providing the tropopause climatology, and Erich Roeckner (Max-Planck-Institut für Meteorologie) for providing the SST climatologies for the $\mathrm{C}$ and A run. Comments of two anonymous reviewers helped improve the manuscript, and are greatly appreciated.

\section{REFERENCES}

Andrews, D. G., J. R. Holton, and C. B. Leovy, 1987: Middle Atmosphere Dynamics. Academic Press, $490 \mathrm{pp}$.

Baldwin, M. P., and T. J. Dunkerton, 1999: Propagation of the Arctic Oscillation from the stratosphere to the troposphere. J. Geophys. Res., 104, 30 937-30946.

Boville, B. A., 1984: The influence of the polar night jet on the tropospheric circulation in a GCM. J. Atmos. Sci., 41, 11321142 .

Brühl, C., 1993: Atmospheric effects of stratospheric aircraft. Report of the 1992 Models and Measurements Workshop, NASA Ref. Publ. 1292 II, VII, 240 pp.

Butchart, N., and A. A. Scaife, 2001: Removal of chlorofluorocarbons by increased mass exchange between the stratosphere and troposphere in a changing climate. Nature, 410, 799-802.

Charney, J. G., and P. G. Drazin, 1961: Propagation of planetaryscale disturbances from the lower into the upper atmosphere. $J$. Geophys. Res., 66, 83-109.

Fels, S. B., J. D. Mahlman, M. D. Schwarzkopf, and R. W. Sinclair, 1980: Stratospheric sensitivity to perturbations in ozone and carbon dioxide: Radiative and dynamical response. J. Atmos. Sci. 37, 2265-2297.

Fyfe, J. C., G. J. Boer, and G. M. Flato, 1999: The Arctic and Antarctic Oscillations and their projected changes under global warming. Geophys. Res. Lett., 26, 1601-1604.

Gillett, N. P., M. R. Allen, and K. D. Williams, 2002: The role of stratospheric resolution in simulating the Arctic Oscillation response to greenhouse gases. Geophys. Res. Lett., 29, 1500-1503. , ——, and — 2003: Modelling the atmospheric response to doubled $\mathrm{CO}_{2}$ and depleted stratospheric ozone using a stratosphere-resolving coupled GCM. Quart. J. Roy. Meteor. Soc., 129, 947-966.

Hartley, D. E., J. Villarin, R. X. Black, and C. A. Davis, 1998: A new perspective on the dynamical link between the stratosphere and troposphere. Nature, 391, 471-474.

Haynes, P. H., C. J. Marks, M. E. McIntyre, T. G. Shepherd, and K P. Shine, 1991: On the "downward control" of extratropical diabatic circulation by eddy-induced mean zonal forces. J. Atmos. Sci., 48, 651-678.

Hines, C. O., 1997a: Doppler spread parameterization of gravity wave momentum deposition in the middle-atmosphere. Part 1: Basic formulation. J. Atmos. Sol. Terr. Phys., 59, 371-386.

_ 1997b: Doppler spread parameterization of gravity wave momentum deposition in the middle-atmosphere. Part 2: Broad and quasi-monochromatic spectra and implementation. J. Atmos. Sol. Terr. Phys., 59, 387-400.
Holton, J. R., P. H. Haynes, M. E. McIntyre, A. R. Douglass, R. B. Rood, and L. Pfister, 1995: Stratosphere-troposphere exchange. Rev. Geophys., 33, 403-439.

Houghton, J. T., Y. Ding, D. J. Griggs, M. Noguer, P. J. van der Linden, and D. Xiaosu, 2001: Climate Change 2001: The Scientific Basis. Cambridge University Press, 944 pp.

Kodera, K., K. Yamazaki, M. Chiba, and K. Shibata, 1990: Downward propagation of upper stratospheric mean zonal wind perturbation to the troposphere. Geophys. Res. Lett., 17, 1264-1266.

Mahfouf, J. F., D. Cariolle, J. F. Royer, J. F. Geleyn, and B. Timbal, 1994: Response of the Meteo-France climate model to changes in $\mathrm{CO}_{2}$ and sea surface temperature. Climate Dyn., 9, 345-362.

Manzini, E., and N. A. McFarlane, 1998: The effect of varying the source spectrum of a gravity wave parameterization in a middle-atmosphere general circulation model. J. Geophys. Res., 103, 31 523-31 539.

__ _ _ , and C. McLandress, 1997: Impact of the Doppler spread parameterization on the simulation of the middle-atmosphere circulation using the MAECHAM4 general circulation model. $J$. Geophys. Res., 102, 25 751-25 762.

McFarlane, N. A., 1987: The effect of orographically exited gravity wave drag on the general circulation of the lower stratosphere and troposphere. J. Atmos. Sci., 44, 1775-1800.

Paeth, H., A. Hense, R. Glowienka-Hense, S. Voss, and U. Cubasch, 1999: The North Atlantic Oscillation as an indicator for greenhouse-gas induced regional climate change. Climate Dyn., 15, 953-960.

Rind, D., R. Suozzo, N. K. Balachandran, and M. J. Prather, 1990: Climate change and the middle-atmosphere. Part I: The doubled $\mathrm{CO}_{2}$ climate. J. Atmos. Sci., 47, 475-494.

_, D. Shindell, P. Lonergan, and N. K. Balachandran, 1998: Climate change and the middle-atmosphere. Part III: The doubled $\mathrm{CO}_{2}$ climate revisited. J. Climate, 11, 876-894.

_ P. Lonergan, N. K. Balachandran, and D. Shindell, 2002: $2 \times$ $\mathrm{CO}_{2}$ and solar variability influences on the troposphere through wave-mean flow interactions. J. Meteor. Soc. Japan, 80, 811830.

Roeckner, E., and Coauthors, 1996: The atmospheric general circulation model ECHAM4: Model description and simulation of present day climate. Max-Planck Institute for Meteorology Rep. 218, Hamburg, Germany, 90 pp.

Rosenlof, K. H., and J. R. Holton, 1993: Estimates of the stratospheric residual circulation using the downward control principle. $J$. Geophys. Res., 98, $10465-10479$.

Shindell, D. T., D. Rind, and P. Lonergan, 1998: Increased polar stratospheric ozone losses and delayed eventual recovery owing to increasing greenhouse-gas concentrations. Nature, 392, 589592.

_ _ R. L. Miller, G. Schmidt, and L. Pandolfo, 1999: Simulation of recent northern winter climate trends by greenhouse-gas forcing. Nature, 399, 452-455.

-, G. A. Schmidt, R. L. Miller, and D. Rind, 2001: Northern Hemisphere winter climate response to greenhouse gas, ozone, solar, and volcanic forcing. J. Geophys. Res., 106, 7193-7210.

Sigmond, M., P. C. Siegmund, and H. Kelder, 2003: Analysis of the coupling between the stratospheric meridional wind and the surface level zonal wind during 1979-93 Northern Hemisphere extratropical winters. Climate Dyn., 21, 211-219.

Thompson, D. W. J., and J. M. Wallace, 1998: The Arctic Oscillation signature in the wintertime geopotential height and temperature fields. Geophys. Res. Lett., 25, 1297-1300.

-,- , and G. C. Hegerl, 2000: Annular modes in the extratropical circulation. Part II: Trends. J. Climate, 13, 1018-1036. 